\title{
Comparison of Physicochemical Characteristics of Starch Isolated from Sweet and Grain Sorghum
}

\author{
Abuelgasim Mohamed Ahmed, ${ }^{1,2}$ Changquan Zhang, and Qiaoquan Liu' \\ ${ }^{1}$ Key Laboratory of Crop Genetics and Physiology of Jiangsu Province, Co-Innovation Center for Modern Production Technology of \\ Grain Crops, College of Agriculture, Yangzhou University, Yangzhou, Jiangsu 225009, China \\ ${ }^{2}$ Department of Botany and Agricultural Biotechnology, Faculty of Agriculture, University of Khartoum, Khartoum, Sudan
}

Correspondence should be addressed to Qiaoquan Liu; qqliu@yzu.edu.cn

Received 27 March 2016; Revised 2 June 2016; Accepted 5 June 2016

Academic Editor: Yves Grohens

Copyright (c) 2016 Abuelgasim Mohamed Ahmed et al. This is an open access article distributed under the Creative Commons Attribution License, which permits unrestricted use, distribution, and reproduction in any medium, provided the original work is properly cited.

\begin{abstract}
The worldwide interest about sweet sorghum (Sorghum bicolor L. Moench) goes towards stem sugar, but little has been focused on its grain. The starches were isolated from the grains of eight sweet and four grain sorghum varieties, and their physical, chemical, and morphological properties were carefully compared. The results reflected that starch from sweet varieties usually had larger granule size than that from grain ones, especially from two sweet varieties GL- 4 and GL- 6 with the granule size of $15.49 \mu \mathrm{m}$ and $15.67 \mu \mathrm{m}$, respectively. The amylose content of sweet varieties starch was lower than that of grain ones. For water solubility index, starch from sweet varieties ranked top, whereas that from grain varieties ranked top for swelling power. The starch from both sweet and grain had A-type crystalline pattern, while the data from ${ }^{13} \mathrm{C}$ NMR reflected pattern differences for $\mathrm{C}_{1}$ and $\mathrm{C}_{6}$ resonance between sweet and grain varieties. Chains length distribution from sweet varieties debranched starch was found a little different from grain one. The starch particles surface of sweet sorghum was smooth with some dents, while that from grain was smooth without appearance of dents. As sweet sorghum has ability to withstand harsh environments where other crops do not and is characterized by low production cost, the extensive potential existed for starch from sweet varieties to be used in starch industries.
\end{abstract}

\section{Introduction}

Sorghum (Sorghum bicolor L. Moench), mostly cultivated across the world in the warmer climatic areas, is quantitatively the world's fifth largest most important cereal grain after wheat, maize, rice, and barley [1]. Sorghum is usually classified into grain and sweet types according to their final utilization. The grain sorghum is mainly used as a principal food in tropical areas and sometimes as raw materials for alcoholic beverages, while the sweet type serves as a material for sweetener syrup $[2,3]$. Taylor et al. (2006) mentioned that sweet sorghum thrived better under drier and warmer conditions than many other crops and is grown primarily for forage, silage, and syrup production due to the high biomass and sugar content [1]. Elkhalifa and Bernhardt (2013) defined sweet sorghum as a variety of common grain sorghum and the essence of sweet sorghum is not from its seed but from its stalk [2]. Most of the sweet sorghum variety is with low grain weight per spike and grain yield, and there is a significant negative relationship between grain yield and stalk sugar [4]. As more than 800 million people suffer from hunger and malnutrition in Africa, Asia, Latin America, and even Europe and USA, development of sweet sorghum will play an important role in promoting the development of agricultural production, livestock husbandry, and energy sources.

Among carbohydrate polymers, starch is currently enjoying attention owing to its usefulness in different food products. Sorghum, like other cereals, is rich in starch, a major storage form for carbohydrates, which makes up about 60$80 \%$ of normal kernels and has an excellent potential for industrial applications $[5,6]$. Starch is composed almost entirely of the polysaccharides amylose and amylopectin. The physical arrangement of amylose and amylopectin and the interaction between starch molecules and other food components determine the physicochemical and functional properties of starch. These properties affect the quality of 
starch based products and are essential to determine potential applications of starch [7]. Udachan et al. (2012) clarified that one way of using surplus sorghum is by way of producing starch and starch based sweeteners; the process is likely to be economical as sorghum is available on the large scale with low cost [8]. Singh et al. (2011) reported that sorghum starch had an excellent potential for global industrial applications. Therefore, further characterization is needed to understand the difference of physiochemical and functional properties between starches from sweet and grain sorghum starch [9]. For measurement of thermal properties, the differential scanning calorimetry (DSC) has been proven to be an extremely valuable tool to quantify the gelatinization of starch and has been widely used to study the thermal behaviors of starches [10-13]. The gelatinization of starch is very important in food processing and has been extensively studied in food science for decades [14-18], in particular with higher water content as mentioned by Liu et al. (2006) [18].

Much of the information about the crystalline properties of starch granule had been acquired from X-ray powder diffraction studies. According to several studies, starch could be classified into $\mathrm{A}, \mathrm{B}$, and $\mathrm{C}$ forms. In the native granular forms, the A pattern is associated mainly with cereal starches, while the B form is usually obtained from tuber starches. The $\mathrm{C}$ pattern is a mixture of both $\mathrm{A}$ type and $\mathrm{B}$ type but also occurs naturally, for example, smooth-seeded pea starch [19]. A widely accepted model of a typical cereal starch granule involves alternating amorphous and crystalline lamellae, in which the two main components, amylose and amylopectin, are embedded.

In recent years, ${ }^{13} \mathrm{C}$ solid-state Nuclear Magnetic Resonance $\left({ }^{13} \mathrm{C}\right.$-NMR) has been widely used to study native products because it can observe structural changes of starch samples in the solid, and it is essentially nondestructive. Although X-ray powder diffraction can monitor crystal structure and relative amounts of crystalline and amorphous phases in starch, it is only sensitive to long-range order, while NMR is sensitive to short-range order as discussed by Saitô et al. (1991), being especially suitable for fewer crystalline samples [20]. Combination of both techniques has provided much important information about secondary structure and molecular order of a number of molecular systems [21, 22], and the starch profiles of ${ }^{13} \mathrm{C}$-NMR were also well studied by many researchers like Gidley and Bocick (1985) and $\mathrm{Xu}$ and Seib (1997) [21, 23].

Gel permeation chromatography (GPC) is a common technique to analyze starch structure including size exclusion chromatography as mentioned by Syahariza et al. (2010) and Yoo and Jane (2002) [24, 25], and the organic solvent most commonly used to dissolve starch is dimethyl sulfoxide (DMSO). DMSO disrupts the intramolecular and intermolecular noncovalent interactions in starch molecules by forming hydrogen bonding between its negatively charged oxygen atom and the hydroxyl groups on starch molecules as well as by forming hydrophobic interactions with starch through its methyl group [26].

All above-mentioned techniques have been introduced to test the grain sorghum starch, but the fine molecular structure of sweet sorghum starch and its physicochemical properties have not been fully investigated. Thus, in present study, eight varieties characterized as sweet type and other four characterized as grain type were used and their physicochemical characteristics were compared after investigation by the above-mentioned techniques. Such information will help identify uses for these sorghum starches in food and other industrial applications.

\section{Materials and Methods}

2.1. Plant Materials. Twelve sorghum genotypes from both China and Sudan were used in this study (Table 1). Among them, eight are sweet types, while four are grain types, and all were planted in the summer of 2013 in the experimental farm of Yangzhou University $\left(32^{\circ} \mathrm{N}, 119^{\circ} \mathrm{E}\right)$ in Yangzhou, Jiangsu province, China, and the mature grains were harvested for following characterizations.

2.2. Starch Isolation. Sorghum starch was isolated from polished sorghum grain by an alkaline protease method with slight modifications [27]. The polished sorghum grains were soaked in three volumes of double distilled water, adjusted to $\mathrm{pH} 8.0-8.5$ with $1.0 \mathrm{M} \mathrm{NaOH}$, and held overnight. The supernatant was discarded, and three volumes of $0.001 \mathrm{M}$ $\mathrm{NaOH}$ were added. The soaked grains were ground in a Warring blender (Blender ULTRA-TURRAX, T25 basic, IKA-WERKE, Guangzhou, China) at the medium speeds for three min and then a volume of $0.001 \mathrm{M} \mathrm{NaOH}$ was added to the slurry up to three volumes. The slurry was adjusted to $\mathrm{pH}$ 9.5 with $1 \mathrm{M} \mathrm{NaOH}$ by using a pH controller (Sartorius PB10). Next, $5 \%$ of protease (Solarbio Science and Technology Co., Ltd., Beijing) was added and mixed with a magnetic stirring bar for $18 \mathrm{~h}$ at $40-45^{\circ} \mathrm{C}$. After that, the slurry was passed through a $75 \mathrm{um}$ screen, and the solids retained on the screen were removed. The sediment was centrifuged at $3800 \mathrm{rpm}$ for $20 \mathrm{~min}$ at $4^{\circ} \mathrm{C}$ temperature, and the dark yellow supernatant was discarded. The sediment was washed with double distilled water and centrifuged for $20 \mathrm{~min}$ and the dark layer was removed. After the supernatant was discarded, the washing and centrifugation steps were repeated three times. Finally, the starch was freeze-dried for $18 \mathrm{~h}$ in the freeze dryer (Christ ALPHA 2-4LD Plus, Germany).

2.3. Amylose Content. Amylose content (AC) of starch was estimated by using the iodine blue value method based on the standard from Ministry of Agriculture, China [28]. The sample (50 mg, dry weight basis, done in triplicate) was dissolved in $0.5 \mathrm{~mL}$ of anhydrous ethanol and $4.5 \mathrm{~mL}$ of $1 \mathrm{M} \mathrm{NaOH}$ in $50 \mathrm{~mL}$ vials. The contents of the vials were vigorously agitated and then heated in a boiling-water bath for $20 \mathrm{~min}$ (with intermittent shaking). The vials were then cooled to ambient temperature. Distilled water was added up to volume and mixed gently and $5 \mathrm{~mL}$ was taken from each sample to opposite $100 \mathrm{~mL}$ volumetric flask containing distilled water. Sodium acetate $(1.0 \mathrm{~mL}, 1.0 \mathrm{M})$ and iodine solutions $(0.04 \%$, $750 \mu \mathrm{L}$ ) were added, respectively. Volumetric flask was shaken gently after the distilled water was added up to volume. 
TABLE 1: The information of sorghum varieties used in this study.

\begin{tabular}{|c|c|c|c|c|}
\hline $\begin{array}{l}\text { Sample } \\
\text { symbol }\end{array}$ & $\begin{array}{c}\text { Original } \\
\text { name }\end{array}$ & Type & Country & Source ${ }^{*}$ \\
\hline WAH & Wad Ahmed & Grain & Sudan & ACSP \\
\hline ARG & $\begin{array}{c}\text { Arfa } \\
\text { gadamak }\end{array}$ & Grain & Sudan & ACSP \\
\hline TAT & Tabat & Grain & Sudan & ACSP \\
\hline GL-1 & $\begin{array}{c}\text { Bai Zhan Gao } \\
\text { Liang }\end{array}$ & Grain & China & ICSCAAS \\
\hline GL-4 & $\begin{array}{l}\text { Huang Zhan } \\
\text { Gao Liang }\end{array}$ & Sweet & China & ICSCAAS \\
\hline GL-6 & Beijing Zhan & Sweet & China & ICSCAAS \\
\hline GL-13 & Tian Xuan 33 & Sweet & China & ICSCAAS \\
\hline GL-14 & $\begin{array}{c}\text { Tian Xuan } \\
184\end{array}$ & Sweet & China & ICSCAAS \\
\hline ZS & Zao Shu & Sweet & China & JCAIAS \\
\hline YT & Yan Tian & Sweet & China & JCAIAS \\
\hline $\mathrm{T}-1$ & Tian Nong 1 & Sweet & China & JCAIAS \\
\hline ST & St008 & Sweet & China & JCAIAS \\
\hline
\end{tabular}

${ }^{*}$ ACSP, Arab Company for Seed Production, Khartoum, Sudan. ICSCAAS, Institute of Crop Science, China Academy of Agricultural Sciences, Beijing, China. JCAIAS, Jiangsu Costal Area Institute of Agriculture Sciences, Yan Cheng, Jiangsu, China.

After $15 \mathrm{~min}$, OD was measured at $620 \mathrm{~nm}$ (Ultrospec 2000, Pharmacia Biotech, Cambridge, England).

2.4. Gel Consistency. Measurement of starch gel consistency was performed by modifying a procedure described by Cagampang et al. (1973) [29]. The modified procedure consisted of combining $100 \mathrm{mg}$ of starch with $0.2 \mathrm{~mL}$ of Thymol blue indicator $(0.025 \%)$ in $12 \mathrm{~cm} \times 13.35 \mathrm{~mm}$ culture tubes oscillated in Vortex Genie2 (Scientific industries, INC, USA). Then $2.0 \mathrm{~mL}$ of $\mathrm{KOH}(0.2 \mathrm{M})$ was added, and the tubes oscillated again. Very fast the mixture was cooked in a vigorously boiling-water bath $\left(101^{\circ} \mathrm{C}\right)$ for $8 \mathrm{~min}$. After cooking, the tubes were allowed to cool in room temperature for $5 \mathrm{~min}$. The mixture was then placed in ice water in an upright position to cool for $20 \mathrm{~min}$. After cooling, the tubes were placed horizontally over ruled logarithmic paper for $1 \mathrm{~h}$ at room temperature $\left(25 \pm 2^{\circ} \mathrm{C}\right)$ and the gel front migration was read to the nearest millimeter. The experiment was done in triplicate.

2.5. Water Solubility and Swelling Power of Starch. The estimation of swelling power (SP) and water solubility index (WSI) of starch was done according to the methods of Radosta et al. (1991) and Tang et al. (2004) with some modifications [30, 31]. A suspension of $0.1 \mathrm{~g}$ of starch and $10.0 \mathrm{~mL}$ of double distilled water (vortex for $10 \mathrm{sec}$ ) was heated in $95^{\circ} \mathrm{C}$ in a water bath for $30 \mathrm{~min}$ (with frequent shake every $2.0 \mathrm{~min}$ ). The suspension was then cooled rapidly at room temperature (in the ice box) and centrifuged for $2000 \mathrm{rpm}$ for $30 \mathrm{~min}$. WSI is reported as the ratio of dry mater supernatant to dry starch sample, whereas SP is reported as the ratio of swelling starch granule's sediment to dry starch. The experiment was done in triplicate.
2.6. Starch Thermal Properties. The thermal property of starch samples was determined by using a differential scanning calorimeter (DSC 200F3, NETZSCH Company, Germany). The samples (5 mg) with excess water $(1: 2)$ were heated at $10^{\circ} \mathrm{C} / \mathrm{min}$ from 20 to $120^{\circ} \mathrm{C}$. Thermal transitions of samples for gelatinization were characterized by $T_{o}$ (onset temperature), $T_{p}$ (peak temperature), $T_{c}$ (conclusion temperature), and $\Delta H$ (enthalpy of gelatinization). The enthalpy calculations were based on dry starch weight. The samples were analyzed twice, and the data were calculated with the software package (DSC 200F3, NETZSCH Company, Germany) [32].

2.7. X-Ray Powder Diffraction. The crystal structure of starch was studied with an X-ray diffractometer (Bruker AXS Model D8 ADVANCE, Germany). Samples were equilibrated in a saturated relative humidity chamber containing access sodium chloride for one week at ambient temperature and dark condition. X-ray diffraction was performed on an Xray diffractometer with copper-cobalt radiation. Signals of the reflection angle of $2 \theta$, from $3^{\circ}$ to $40^{\circ}$, were recorded. The degree of crystallinity of samples was quantitatively estimated following the method of Nara and Komiya (1983) [33]. The ratio of the upper area (peaks area) to total diffraction area was taken as the degree of crystallinity $[19,32]$.

2.8. NMR Measurements. A solid-state ${ }^{13} \mathrm{C}$ NMR spectrum was measured on the Bruker Avance 500 solid-state NMR spectrometer at $125.8 \mathrm{MHz}$ and $500.2 \mathrm{MHz}$, respectively. Samples were measured in four $\mathrm{mm} \mathrm{ZrO}_{2}$ rotors with spinning frequencies of eight $\mathrm{kHz}\left({ }^{13} \mathrm{C}-\mathrm{NMR}\right)$. NMR spectra were measured with a contact time of $1 \mathrm{~ms}$ and relaxation delay between two consecutive scans of $4 \mathrm{sec}$. Chemical shifts in the ${ }^{13} \mathrm{C}$-NMR spectra were referred to the carbonyl line of glycine (with a signal at $176 \mathrm{ppm}$ from TMS) by sample replacement. Spin-lattice relaxation times T1(C) of starch were measured with CP by the method of Torchia (1978) [34]. The experimental scheme with a variable spin-lock time within the range $0.1-10 \mathrm{~ms}$ after the proton signal excitation followed by constant contact time was used; the proton spinlocking field in frequency units was $80 \mathrm{kHz}$ [35].

2.9. Morphological Properties of Starch Granules. Scanning electron micrographs (SEM) of starch were obtained with a scanning microscope (Environment Scanning Electron Microscope, model: XL-30ESM, Philips Company, Netherlands). Starch sample was suspended in ethanol (95\%) to obtain $1 \%$ suspension and mounted on circular aluminum stubs with double-sided sticky tape. The starch granules were evenly distributed on the surface of the tape, and the ethanol was allowed to evaporate. The samples were then coated with gold-palladium (60:40), examined, and photographed at an acceleration potential of $10 \mathrm{kV}$ with a magnification of $\times 1000$, $\times 2000, \times 4000$, and $\times 8000$ during micrography [36].

2.10. Gel Permeation Chromatography. Starch (10 mg) was mixed in $5 \mathrm{~mL}$ of sodium acetate buffer $(0.1 \mathrm{M}, \mathrm{pH} 4.2)$ (in a $12 \mathrm{~mL}$ glass vial with a micro stir bar) and heated in a boilingwater bath for $1 \mathrm{~h}$ followed by cooling to room temperature. 
The starch was treated with $13.4 \mu \mathrm{L}$ of $\beta$-amylase $(19 \mu / \mathrm{L}$, Sigma product number A 7005) for $36 \mathrm{~h}$ at $40^{\circ} \mathrm{C}$. The mixture was boiled for $10 \mathrm{~min}$ to deactivate the enzyme followed by cooling to room temperature. The mixture was kept at $-20^{\circ} \mathrm{C}$ for 3-4 $\mathrm{h}$ and then lyophilized in freeze dryer (Christ ALPHA 2-4LD Plus, Germany) according to Asaoka et al. (1985) with some modifications [37]. Four milligrams of debranched starch was mixed with $4 \mathrm{~mL}$ dimethyl sulfoxide (DMSO) and stirred in a boiling-water bath for $24 \mathrm{~h}$. The sample was filtered through a $2 \mu \mathrm{m}$ filter and then $200 \mu \mathrm{L}$ was injected into a PL-GPC 220 instrument (Polymer Laboratories, Inc., Amherst, MA, USA) equipped with three Phenogel columns of different pore sizes $\left(100 \AA, 103 \AA\right.$, and $105 \AA$, Phenogel ${ }^{\mathrm{TM}}$ GPC, $10 \mu \mathrm{m}, 300 \times 7.8 \mathrm{~mm}$ ), a guard column (Phenomenex, Inc., Torrance, CA, USA), and a differential refractive index detector. The eluent system was DMSO containing $5.0 \mathrm{mM}$ $\mathrm{NaNO}_{3}$ at a flow rate of $0.8 \mathrm{~mL} / \mathrm{min}$. The column oven temperature was controlled at $80^{\circ} \mathrm{C}$. Standard dextran (American Polymer Standards Co., Mentor, OH, USA) with different molecular weights (MW) was used for MW calibration according to Zhu et al. (2010) [38].

2.11. Statistical Analysis. Data was analyzed using analysis of variance (ANOVA) procedures of the SPSS version 16.0. Variances were considered at a significant level of 95\% ( $p<$ $0.05)$. Means were compared using Duncan's multiple range test (DMRT) [39]. Unpaired $t$-test was used to compare differences between means.

\section{Results and Discussion}

3.1. Amylose Content and Gel Consistency of the Starches. Amylose and amylopectin are important for food and bioindustry applications, as they have distinctively different structures and physicochemical properties. Amylose contents of starch from eight sweet and four grain sorghum varieties were shown in Table 2. Significant differences were observed among tested varieties $(p<0.05)$, and the AC from grain varieties (average $35.61 \%)$ was significantly $(p<0.05)$ higher from that of sweet varieties (average 23.52\%) (Figure 1(a)). The GL-1 grain variety showed highest AC among all varieties, whereas GL-4 sweet variety showed the lowest AC. Starch from grain varieties had highest AC (ranged from $34.52 \%$ to $36.39 \%$ ) compared with sweet varieties, which ranged from $5.39 \%$ to $33.50 \%$. The current results reflected a vast range for AC (5.39-36.39\%) compared with that of Udachan et al. (2012) (10.80-18.72\%) for their study on four sorghum varieties [8] and Singh et al. (2010) (11.2-22.5\%) for their study on sorghum cultivars grown in Indi [40] and Beta et al. (2001) (24.0-33.0\%) from 95 Zimbabwean sorghum land races [41]. The vast range of AC observed in the current study was in accordance with that mentioned by Zhu (2014); he noticed existence of great genetic variation in $\mathrm{AC}$ of sorghum starch [42], and another study pursued by Hill et al. (2012) revealed a range of AC from $16.1 \%$ to $55.8 \%$ for 55 sorghum genotypes [43]. Starch with variable $\mathrm{AC}$ is of interest because of its utility in different applications and significant effect on the characteristics of final products. Schirmer et al. (2013) postulated that low- and high-amylose
TABle 2: Amylose content (AC), gel consistency (GC), water solubility index (WSI), and swelling power (SP) for starches from sweet and grain varieties.

\begin{tabular}{lcccc}
\hline Sample & AC $(\%)$ & GC $(m m)$ & WSI $(\%)$ & SP $(g / g)$ \\
\hline Grain & & & & \\
GL-1 & $36.39 \pm 0.15^{\mathrm{a}}$ & $118.5 \pm 0.35^{\mathrm{bc}}$ & $10.0 \pm 0^{\mathrm{c}}$ & $11.22 \pm 0.11^{\mathrm{ab}}$ \\
WAH & $35.25 \pm 0.26^{\mathrm{ab}}$ & $112.0 \pm 0.10^{\mathrm{de}}$ & $25.0 \pm 5^{\mathrm{bc}}$ & $20.07 \pm 0.93^{\mathrm{a}}$ \\
ARG & $36.28 \pm 0.26^{\mathrm{a}}$ & $89.0 \pm 0.11^{\mathrm{f}}$ & $30.0 \pm 0^{\mathrm{bc}}$ & $16.21 \pm 0.93^{\mathrm{ab}}$ \\
TAT & $34.52 \pm 0.40^{\mathrm{ab}}$ & $125.5 \pm 0.05^{\mathrm{bc}}$ & $10.0 \pm 0^{\mathrm{c}}$ & $12.33 \pm 1.89^{\mathrm{ab}}$ \\
\hline Sweet & & & & \\
GL-4 & $5.39 \pm 0.18^{\mathrm{e}}$ & $129.5 \pm 0.05^{\mathrm{b}}$ & $95.0 \pm 5^{\mathrm{a}}$ & $3.50 \pm 3.50^{\mathrm{b}}$ \\
GL-6 & $6.71 \pm 0.11^{\mathrm{e}}$ & $157.7 \pm 0.11^{\mathrm{a}}$ & $95.0 \pm 5^{\mathrm{a}}$ & $7.00 \pm 7.00^{\mathrm{ab}}$ \\
GL-13 & $28.41 \pm 0.66^{\mathrm{c}}$ & $126.0 \pm 0.20^{\mathrm{bc}}$ & $35.0 \pm 5^{\mathrm{bc}}$ & $14.85 \pm 2.99^{\mathrm{ab}}$ \\
GL-14 & $24.38 \pm 1.17^{\mathrm{d}}$ & $106.5 \pm 0.25^{\mathrm{e}}$ & $30.0 \pm 0^{\mathrm{bc}}$ & $17.86 \pm 1.57^{\mathrm{ab}}$ \\
ZS & $33.50 \pm 0.04^{\mathrm{ab}}$ & $121.5 \pm 0.05^{\mathrm{bcd}}$ & $40.0 \pm 10^{\mathrm{bc}}$ & $15.69 \pm 1.98^{\mathrm{ab}}$ \\
YT & $29.14 \pm 1.24^{\mathrm{c}}$ & $120.0 \pm 0.10^{\mathrm{bcd}}$ & $25.0 \pm 5^{\mathrm{bc}}$ & $15.43 \pm 1.43^{\mathrm{ab}}$ \\
T-1 & $32.77 \pm 0.04^{\mathrm{b}}$ & $121.0 \pm 0.30^{\mathrm{bcd}}$ & $30.0 \pm 0^{\mathrm{bc}}$ & $15.50 \pm 0.21^{\mathrm{ab}}$ \\
ST & $27.82 \pm 0.29^{\mathrm{c}}$ & $95.0 \pm 0.21^{\mathrm{f}}$ & $15.0 \pm 5^{\mathrm{bc}}$ & $11.72 \pm 1.16^{\mathrm{ab}}$ \\
\hline
\end{tabular}

All data represent the mean of three determinations. Means with the same superscript in each column are not significantly different $(p<0.05)$.

starches provide distinctively different structures and physicochemical properties during their various applications [44]. On the other hand, AC in the starch isolated from sweet sorghum juice was $16.4 \%$ [45], which was also different from $\mathrm{AC}$ of starch isolated from grain. Further efforts to look for the range of $\mathrm{AC}$ in sorghum juice in contrast with that of grain and the correlation between them are needed. Lu et al. (2013) reported that high amylopectin grains of waxy sorghum have a high economic value in the food and bioenergy industries because of their increased starch digestibility and higher ethanol conversion rate compared with wild-type sorghum grains [46]. Consequently, in this study, the starch from sweet varieties showed lower AC and higher amylopectin level compared with that of grain varieties, which make them with substantial potential for industrial uses.

As reported previously, AC could play a major role in swelling, pasting properties, and gel firmness of starch [15, $16,39,47]$. Gel consistency (GC) values ranged from $89.0 \mathrm{~mm}$ to $157.67 \mathrm{~mm}$ among tested varieties (Table 2). GL-6, a sweet variety, showed the highest GC $(157.67 \mathrm{~mm})$, whereas the grain variety ARG showed the lowest GC $(89.0 \mathrm{~mm})$. The range for grain varieties was from $89.0 \mathrm{~mm}$ to $125.5 \mathrm{~mm}$, whereas for sweet varieties it was from $95.0 \mathrm{~mm}$ to $157.67 \mathrm{~mm}$. The values and the range of GC from sweet varieties are generally higher than those from grain ones, while Figure 1(b) shows that the difference was not significant $(p<0.05)$. The highest values for GC observed in this study may be attributed to amylose level as sweet varieties showed lowest values compared with grain ones (Table 2). Furthermore, this notice is in accordance with that mentioned by Lindqvist (1979) and Chanapamokkhot and Thongngam (2007) [39, 47] and Beta et al. (2001) [41]; they noticed that gel hardness was largely determined by the AC of starch.

3.2. Water Solubility Index and Swelling Power. The ability to swell in excess water and solubility of the starches from 


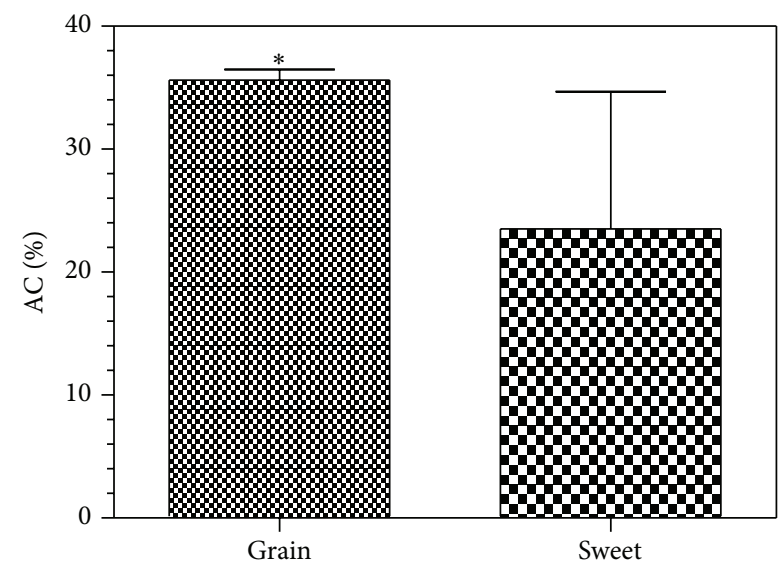

(a)

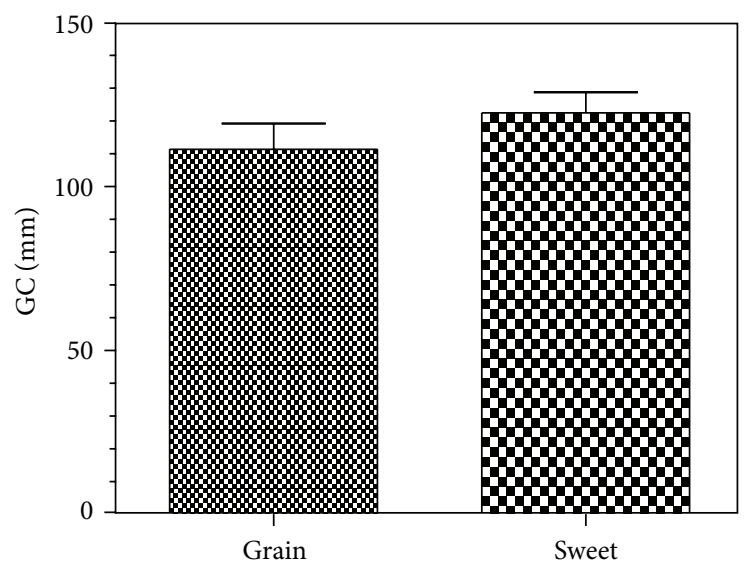

(b)

FIGURE 1: Comparison of the average amylose content (AC) (a) and gel consistency (GC) (b) of starches between sweet and grain varieties. * indicates that significant difference was noticed $(p<0.05)$.

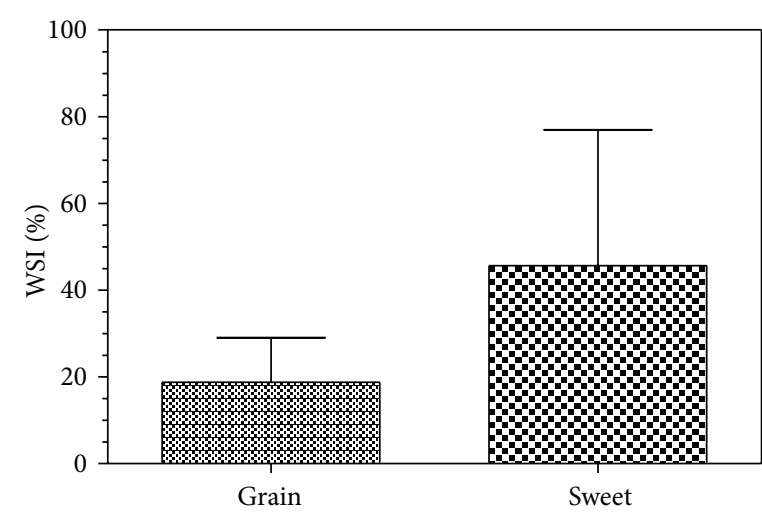

(a)

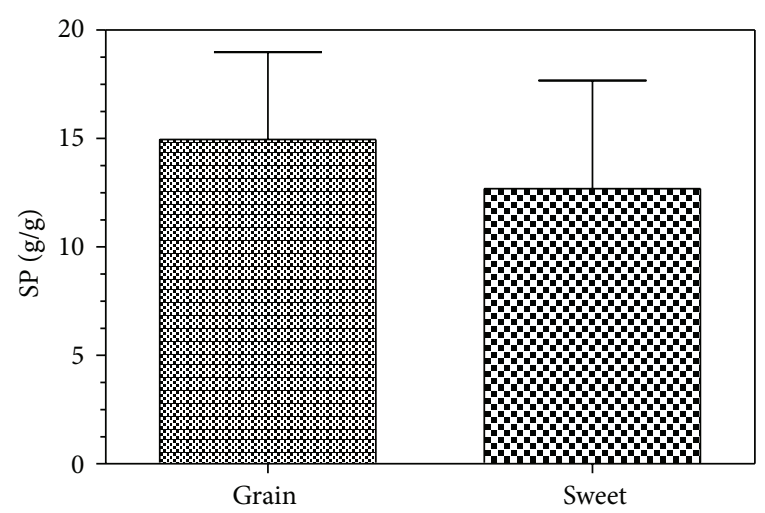

(b)

FIGURE 2: Comparison of water solubility index (WSI) (a) and swelling power (SP) (b) between sweet and grain sorghum varieties starch. No significant difference was noticed $(p<0.05)$.

sweet and grain varieties showed significant differences $(p<$ 0.05 ) (Table 2). Water solubility index (WSI) for all varieties ranged from 10.0 to $95.0 \%$, and the swelling power (SP) for all varieties had the range from 3.0 to $20.0 \mathrm{~g} / \mathrm{g}$. Among grain varieties, TAT showed the highest WSI (30.0\%), whereas ARG showed the highest SP $(20.07 \mathrm{~g} / \mathrm{g})$; but GL-1 showed the lowest values for WSI $(10.0 \%)$ and SP (11.22 g/g). Among sweet varieties, GL-4 showed the highest WSI (95.0\%) and the lowest SP $(3.0 \mathrm{~g} / \mathrm{g})$, while GL-14 showed the highest SP $(17.0 \mathrm{~g} / \mathrm{g})$ and ST showed the lowest WSI (15.0\%). Starch with highest WSI (95.0\%) was obtained from sweet varieties GL-4 and GL-6, whereas the lowest WSI value (10.0\%) was obtained from grain varieties GL-1 and WAD (Table 2). Starch with highest SP was observed from a grain variety ARG, and the lowest SP was observed from a sweet variety GL-4. In current study, sweet varieties showed highest WSI compared to grain varieties, whereas grain varieties showed highest SP compared to sweet ones (Figures 2(a) and 2(b)). When starch molecules are heated in excess water, the crystalline structure is disrupted and water molecules become linked by hydrogen bonding to the exposed hydroxyl groups of amylose and amylopectin, which causes an increase in granule swelling and solubility. The differences in starch swelling power and water solubility index between grain and sweet varieties could be probably attributed to the amylose to amylopectin ratio and to the characteristics of amylose and amylopectin in terms of degree and length of branching and conformation as reported previously by Hoover (2001) [48]. Also the differences shown in the current study for morphological structure of starch granules were interplayed in the differences which have been noticed for SP and WSI [49]. The SP of starch indicates the degree of water absorption of starch granules, and the solubility reflects the degree of dissolution during the starch swelling procedure [50]. Consequently, the current study showed the lower degree of water absorption for sweet varieties compared with that of grain varieties. WSI and SP provide evidence of the magnitude of the interaction between starch chains within both the amorphous and crystalline domains as mentioned by Singh et al. (2003) [51].

Besides, the range for SP in present study was from 3.0 to $20.0 \mathrm{~g} / \mathrm{g}$, a little different from that reported by Singh et al. (2010). They reported that the SP of starches from 
TABLE 3: Thermal properties of starch from sweet and grain sorghum varieties.

\begin{tabular}{lcccc}
\hline Sample & $T_{o}\left({ }^{\circ} \mathrm{C}\right)$ & $T_{p}\left({ }^{\circ} \mathrm{C}\right)$ & $T_{c}\left({ }^{\circ} \mathrm{C}\right)$ & $(\Delta) H(\mathrm{~J} / \mathrm{g})$ \\
\hline Grain & & & \\
GL-1 & $72.50 \pm 0.00^{\mathrm{a}}$ & $76.15 \pm 0.05^{\mathrm{a}}$ & $81.55 \pm 0.05^{\mathrm{a}}$ & $12.43 \pm 0.17^{\mathrm{abc}}$ \\
WAH & $70.60 \pm 0.00^{\mathrm{c}}$ & $74.15 \pm 0.05^{\mathrm{bc}}$ & $80.10 \pm 0.20^{\mathrm{cd}}$ & $13.40 \pm 0.21^{\mathrm{ab}}$ \\
ARG & $71.00 \pm 0.00^{\mathrm{b}}$ & $74.4 \pm 0.10^{\mathrm{bc}}$ & $80.30 \pm 0.20^{\mathrm{bcd}}$ & $13.14 \pm 0.63^{\mathrm{ab}}$ \\
TAT & $71.20 \pm 0.00^{\mathrm{b}}$ & $74.65 \pm 0.05^{\mathrm{b}}$ & $79.95 \pm 0.05^{\mathrm{d}}$ & $12.68 \pm 0.28^{\mathrm{ab}}$ \\
\hline Sweet & & & & \\
GL-4 & $69.65 \pm 0.05^{\mathrm{d}}$ & $74.35 \pm 0.05^{\mathrm{bc}}$ & $81.15 \pm 0.05^{\mathrm{ab}}$ & $13.50 \pm 0.74^{\mathrm{ab}}$ \\
GL-6 & $70.30 \pm 0.00^{\mathrm{c}}$ & $73.95 \pm 0.05^{\mathrm{c}}$ & $80.90 \pm 0.10^{\mathrm{abc}}$ & $14.06 \pm 0.25^{\mathrm{a}}$ \\
GL-13 & $69.15 \pm 0.05^{\mathrm{e}}$ & $72.20 \pm 0.10^{\mathrm{d}}$ & $77.70 \pm 0.20^{\mathrm{f}}$ & $12.63 \pm 0.53^{\mathrm{abc}}$ \\
GL-14 & $61.05 \pm 0.05^{\mathrm{j}}$ & $66.40 \pm 0.00^{\mathrm{h}}$ & $73.80 \pm 0.30^{\mathrm{h}}$ & $8.85 \pm 0.34^{\mathrm{de}}$ \\
ZS & $66.35 \pm 0.05^{\mathrm{h}}$ & $70.85 \pm 0.05^{\mathrm{e}}$ & $76.60 \pm 0.20^{\mathrm{g}}$ & $10.48 \pm 0.51^{\mathrm{cd}}$ \\
YT & $63.25 \pm 0.05^{\mathrm{i}}$ & $68.20 \pm 0.20^{\mathrm{f}}$ & $47.60 \pm 0.10^{\mathrm{h}}$ & $7.85 \pm 0.47^{\mathrm{e}}$ \\
T-1 & $68.75 \pm 0.05^{\mathrm{f}}$ & $72.65 \pm 0.05^{\mathrm{d}}$ & $78.75 \pm 0.05^{\mathrm{e}}$ & $12.04 \pm 0.21^{\mathrm{abc}}$ \\
ST & $67.75 \pm 0.15^{\mathrm{g}}$ & $71.20 \pm 0.20^{\mathrm{e}}$ & $76.90 \pm 0.20^{\mathrm{fg}}$ & $11.46 \pm 0.12^{\mathrm{bc}}$ \\
\hline All & & &
\end{tabular}

All data represent the mean of three determinations.

Means with the same superscript in each column are not significantly different $(p<0.05)$.

different sorghum varieties had the range between $6.2 \mathrm{~g} / \mathrm{g}$ and $15.3 \mathrm{~g} / \mathrm{g}$ [40]. Subrahmanyam and Hoseney (1995) noticed the SP between $13.8 \mathrm{~g} / \mathrm{g}$ and $15.2 \mathrm{~g} / \mathrm{g}$, which was also different from above-mentioned results [52]. For WSI, the range was between 10.0 and $95.0 \%$ in the current study and between $17.4 \%$ and $22.5 \%$ in the previously mentioned study for starches isolated from seven US sorghum cultivars [52]. Olayinka et al. (2008) mentioned SP of $8.79 \mathrm{~g} / \mathrm{g}$ and solubility of $5.0 \%$ for starch isolated from Nigerian sorghum [53]. The above differences among different studies might be due to the different methods of starch isolation, different AC, different molar proportion of amylopectin A and B1, and different environmental condition [54].

3.3. Thermal Properties of Starch. The gelatinization properties of starch isolated from sweet and grain sorghum measured using DSC are summarized in Table 3. There had been significant difference among all varieties for DSC parameters studied $(p<0.05)$. For $T_{o}, T_{p}$, and $T_{c}$, the lowest degrees were noticed from sweet varieties compared with grain varieties. GL-1 grain variety ranked top among grain verities for those three parameters and even for sweet varieties showing the highest values of $72.5,76.15$, and $81.55^{\circ} \mathrm{C}$, respectively. Sweet variety GL-14 showed lowest values for $T_{o}$ and $T_{p}$ (61.05 and $66.4^{\circ} \mathrm{C}$, resp.), whereas sweet variety YT showed the lowest value for $T_{c}\left(47.6^{\circ} \mathrm{C}\right)$ among all varieties. Among sweet varieties, GL- 4 showed the highest values for $T_{p}$ and $T_{c}$ (74.35 and $81.15^{\circ} \mathrm{C}$, resp.), whereas GL- 6 showed the highest value for $T_{o}\left(70.3^{\circ} \mathrm{C}\right)$. For enthalpy of gelatinization $(\Delta H)$ among all varieties, sweet variety GL- 6 showed the highest degree $(14.06 \mathrm{~J} / \mathrm{g})$, whereas another sweet variety YT showed the lowest degree $(7.85 \mathrm{~J} / \mathrm{g})$, while grain varieties had the range from $12.43 \mathrm{~J} / \mathrm{g}$ for GL-1 to $13.4 \mathrm{~J} / \mathrm{g}$ for WAD, which revealed intermediate degrees. Figures $3(\mathrm{a})$ and $3(\mathrm{~b})$ show that the degrees from grain varieties studied for $T_{o}$ and $T_{p}$ exhibited
TABle 4: The XRD and ${ }^{13} \mathrm{C}$ CP/MAS NMR chemical shifts of starches from sweet and grain sorghum varieties.

\begin{tabular}{lcccccc}
\hline \multirow{2}{*}{ Sample } & \multicolumn{5}{c}{ XRD } & \multicolumn{5}{c}{ NMR chemical shifts (ppm) } \\
& RC (\%) & $\begin{array}{r}\text { Crystal } \\
\text { pattern }\end{array}$ & $\mathrm{C}_{1}$ & $\mathrm{C}_{4}$ & $\mathrm{C}_{2}, \mathrm{C}_{3}$, & $\mathrm{C}_{6}$ \\
\hline Grain & & & & & & \\
GL-1 & 16.42 & $\mathrm{~A}$ & 102.23 & 82.40 & 72.61 & 62.27 \\
WAH & 15.00 & $\mathrm{~A}$ & 102.13 & 82.15 & 72.71 & 62.32 \\
ARG & 15.27 & $\mathrm{~A}$ & 102.08 & 82.10 & 72.66 & 62.27 \\
TAT & 15.22 & $\mathrm{~A}$ & 102.81 & 82.60 & 72.76 & 62.47 \\
\hline Sweet & & & & & & \\
GL-4 & 25.14 & $\mathrm{~A}$ & 101.69 & 94.67 & 72.66 & 62.37 \\
GL-6 & 24.82 & $\mathrm{~A}$ & 101.73 & 95.45 & 72.71 & 62.37 \\
GL-13 & 18.31 & $\mathrm{~A}$ & 102.08 & 82.50 & 72.66 & 62.47 \\
GL-14 & 15.34 & $\mathrm{~A}$ & 102.18 & 82.40 & 72.66 & 62.12 \\
ZS & 17.82 & $\mathrm{~A}$ & 101.93 & 81.90 & 72.61 & 62.37 \\
YT & 19.10 & $\mathrm{~A}$ & 102.03 & 82.05 & 72.71 & 62.32 \\
T-1 & 17.87 & $\mathrm{~A}$ & 102.13 & 82.10 & 72.66 & 62.27 \\
ST & 16.91 & A & 101.98 & 82.50 & 72.66 & 62.27 \\
\hline
\end{tabular}

high significant $(p<0.01)$ differences from sweet varieties, whereas for $T_{c}$ differences they were not significant $(p<0.05)$ (Figure 3(c)). $\Delta H$ of sweet varieties was a little bit higher than that of grain varieties, but the differences were not significant $(p<0.05)$ as presented in Figure 3(d). The highest $\Delta H$ which appeared by starch isolated from sweet varieties indicates a high level of the starch chain intramolecular bond. This high level may also be attributed to the increased rigidity of the starch granules as in current study sweet varieties showed starch granules size larger than that of grain ones. The enthalpy of starch gelatinization $(\Delta H)$ is the energy necessary to transform the granule structure from a crystalline to an amorphous state as discussed by Hasjim et al. (2013) [55]. As in the current study, this parameter showed higher degrees for sweet varieties starch compared with grain varieties starch and may relatively be attributed to the higher relative crystallinity of the former. Ji et al. (2004) hypothesized that $T_{o}$ would be a measure of the perfection of starch crystallites, and the more perfect crystallites, the higher gelatinization onset temperatures [56]. The lowest degree noticed in this study for $T_{o}$ from sweet varieties compared with that of grain varieties was due to the less perfect crystallites of sweet sorghum starch. The gelatinization temperature observed in the current study for sorghum starch is of similar range to that reported by Akingbala et al. (1988) $\left(75.6 \pm 0.9^{\circ} \mathrm{C}\right)$ for starch isolated from 24 sorghum varieties [57]. Also the current study is not far from that postulated by Sun et al. (2014) in their study on sorghum starch for $T_{o}, T_{c}, T_{p}$, and $\Delta H$ (64.60, $74.26,69.42^{\circ} \mathrm{C}$, and $9.02 \mathrm{~J} / \mathrm{g}$, resp.) [32].

3.4. Crystalline Pattern of Starch. Table 4 lists the crystalline pattern and relative crystallinity (RC), calculated from the ratio of diffraction peak area to total diffraction area, of starch from different sweet and grain sorghum varieties. 


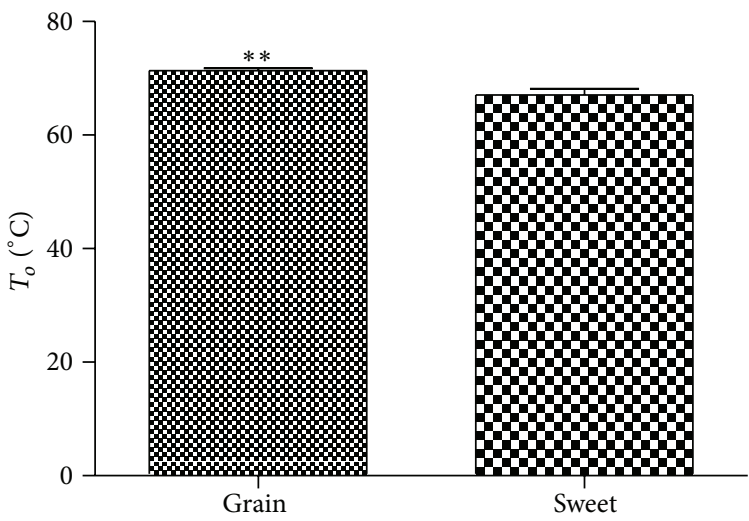

(a) Onset temperature

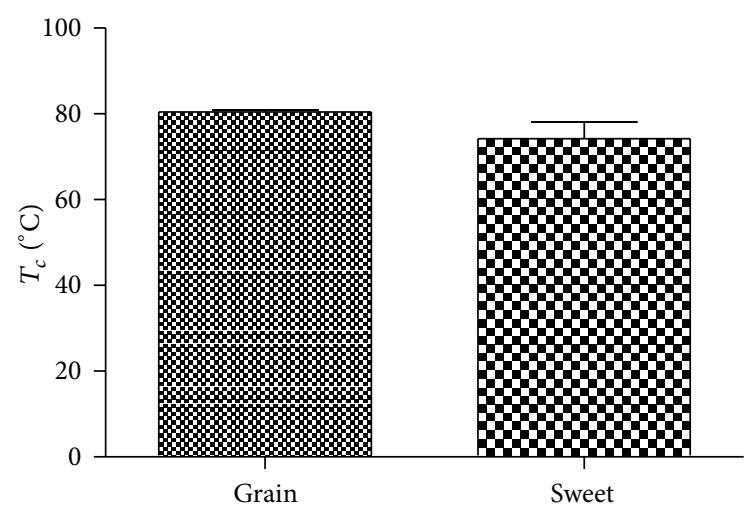

(c) TC

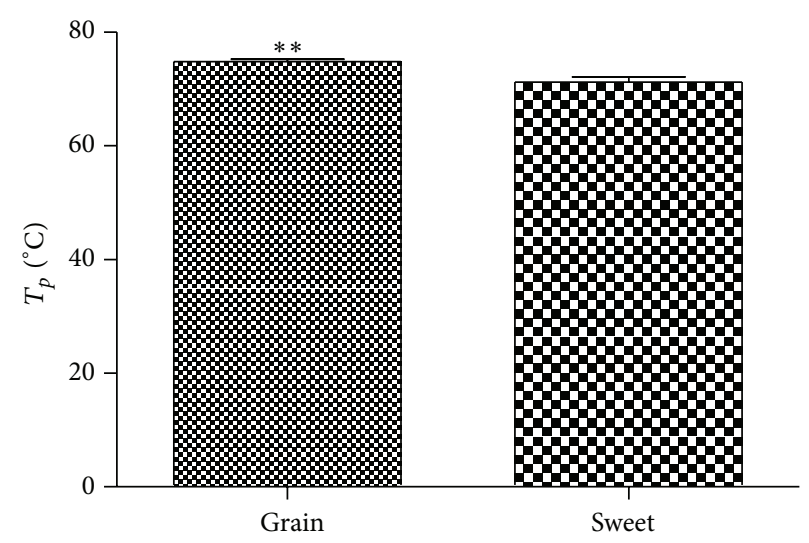

(b) TP

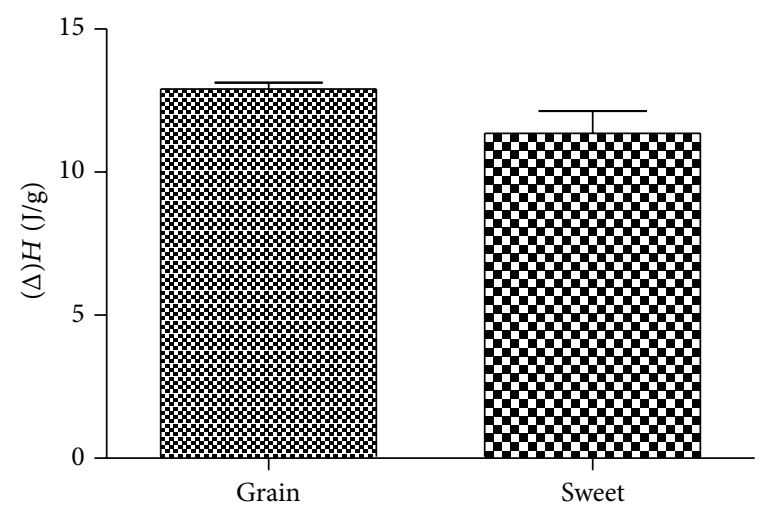

(d) $(\Delta) H(\mathrm{~J} / \mathrm{g})$

FIgURE 3: Comparison of starch thermal properties between sweet and grain sorghum varieties. (a)-(d) represent $T_{o}, T_{p}, T_{c}$, and $\Delta H$, respectively. $* *$ indicates that high significant difference $(p<0.001)$ was noticed.

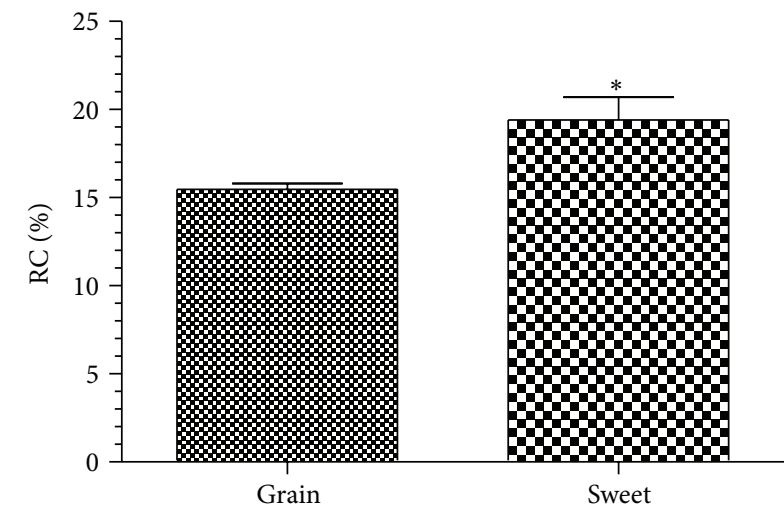

(a)

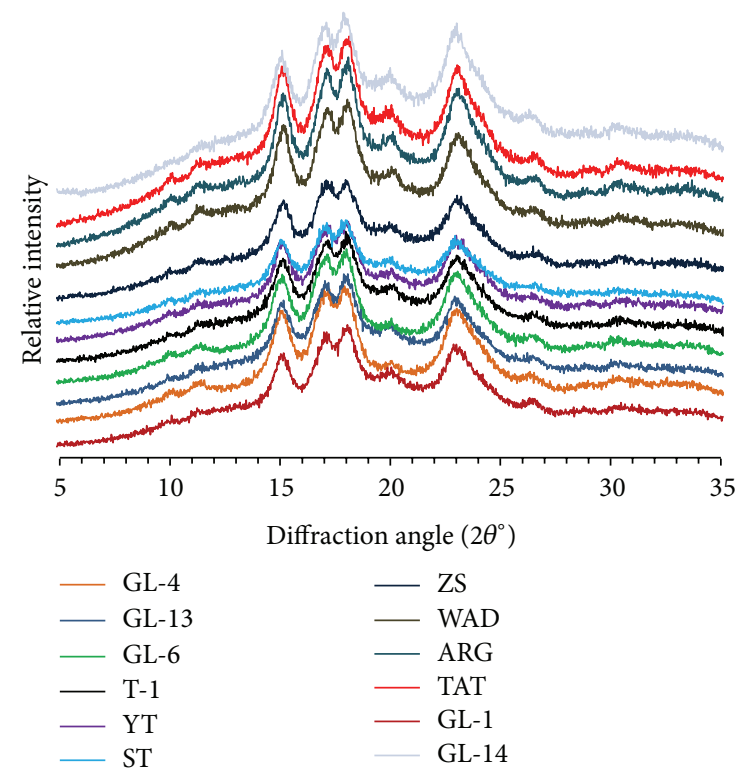

(b)

FIGURE 4: Comparison of relative crystallinity (RC) (a) and XRD spectrograph (b) of starches from sweet and grain varieties. * indicates significant difference $(p<0.05)$ was noticed. 


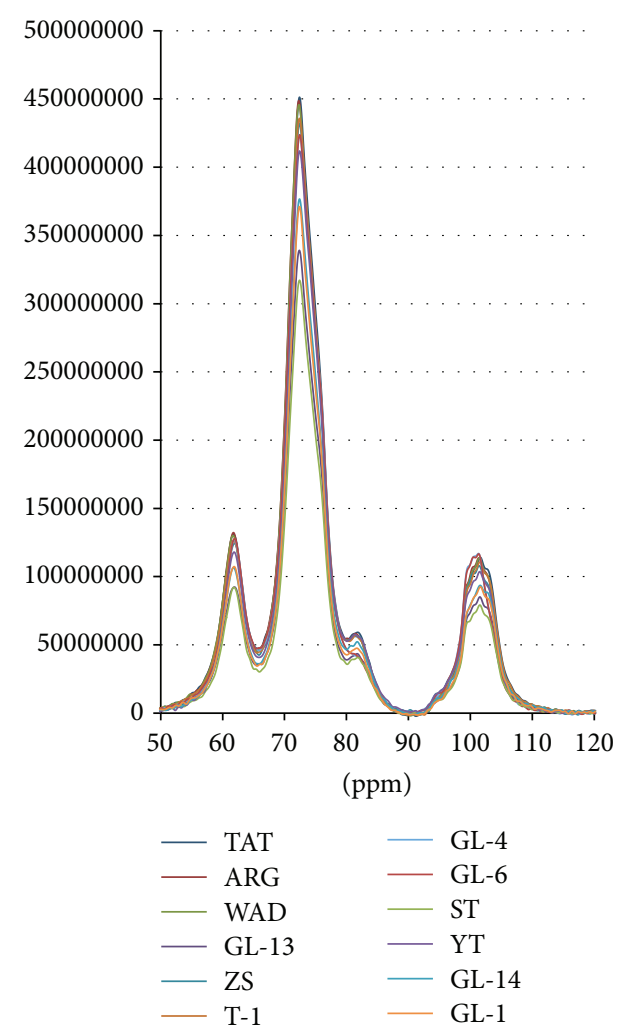

(a)

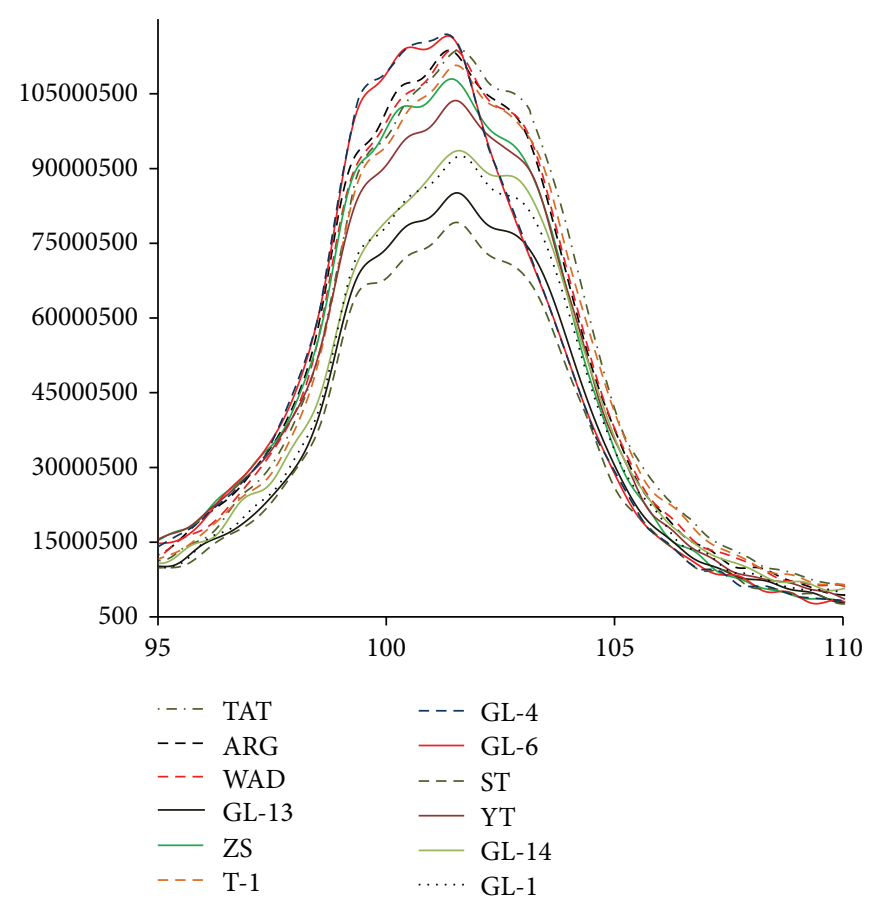

(b)

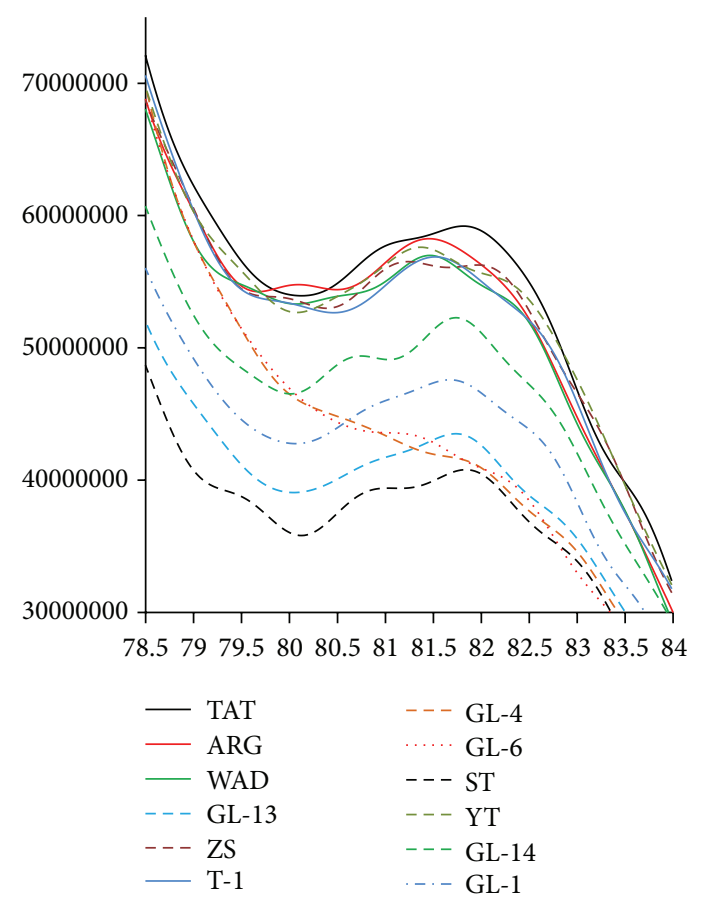

(c)

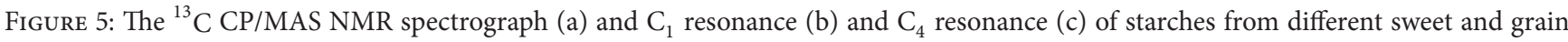
sorghum varieties. 


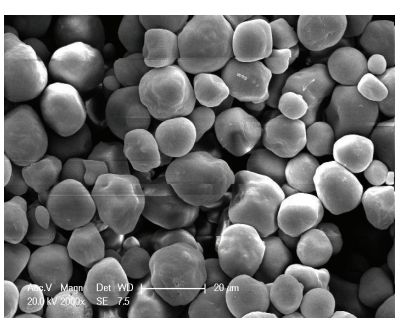

(a) ARG

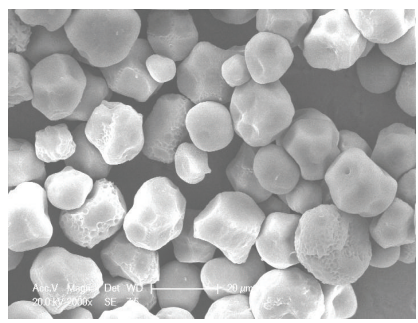

(e) GL-6

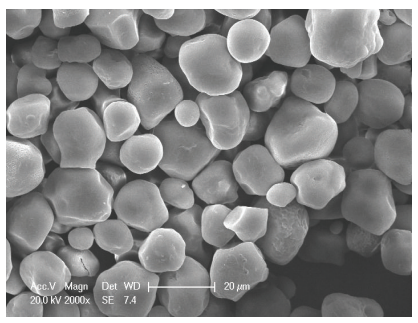

(i) $\mathrm{YT}$

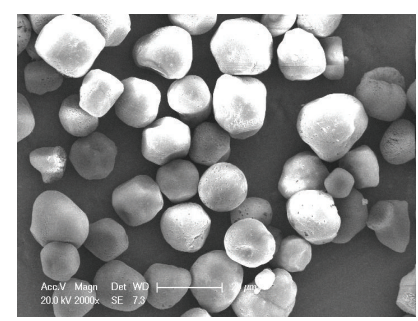

(b) GL-1

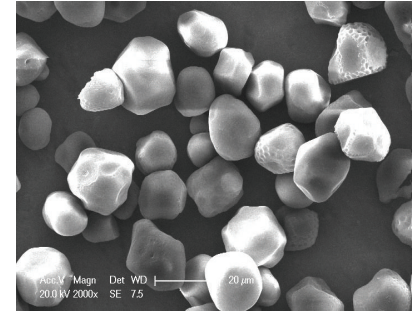

(f) $\mathrm{T}-1$

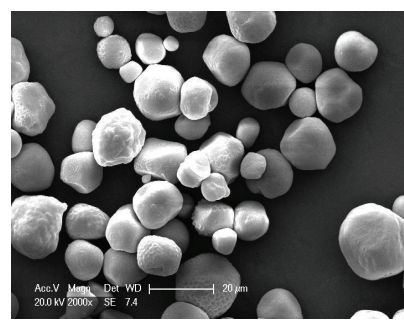

(j) ZS

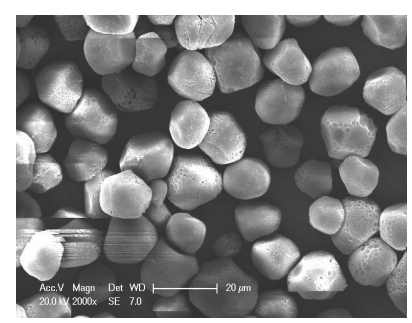

(c) GL-13

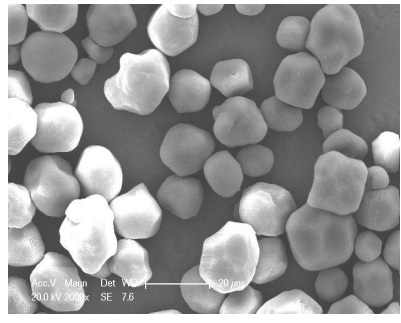

(g) TAT

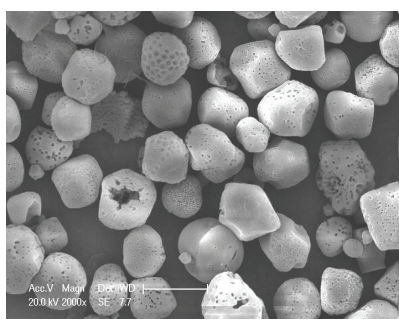

(k) ST

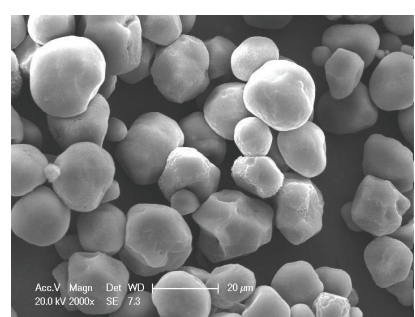

(d) GL-4

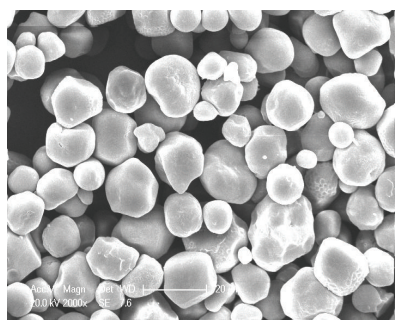

(h) WAH

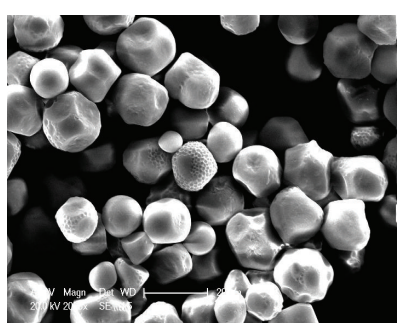

(1) GL-14

FIGURE 6: SEM images (2000x) of starch granules from different sweet and grain sorghum.

Sweet varieties studied showed high RC from grain varieties. Grain varieties had the range of RC from $15.00 \%$ to $16.42 \%$, whereas sweet varieties ranged from $15.34 \%$ to $25.14 \%$. The sweet variety GL-4 showed the highest RC (25.14\%) among all varieties, whereas the grain variety WAD showed the lowest one (15.0\%). Clearly sweet varieties studied reflected RC significantly $(p<0.05)$ higher than that from grain varieties (Figure 4(a)). Figure 4(b) shows starch crystalline properties of sweet and grain varieties studied using XRD. The results showed that both sweet and grain sorghum starches presented type A crystalline pattern as described by Zobel (1988) with strong peaks at around $15^{\circ}$ and $23^{\circ}$ and an unresolved doublet at around $17^{\circ}$ and $18^{\circ}$ of diffraction angle $2 \theta$ [58]. The peaks noticed for the current starches that appeared at $15^{\circ}, 17^{\circ}, 18^{\circ}$, and $23^{\circ}(2 \theta)$ were also found in previous studies, such as Shin et al. (2004) for their study about Korean raw waxy sorghum starch [59], Boudries et al. (2009) for their study about sorghum starch cultivated in the Algerian Sahara [7], and Alvesa et al. (2014) for their study about starch isolated from sugarcane and sweet sorghum juice [45]. The A-diffraction pattern is typical of cereal starches and is characterized by double helix formed by packed amylose and amylopectin molecules in a monocyclic arrangement [60]. The current range for $\mathrm{RC}$ is in accordance with that reported by Zobel (1988); he mentioned that the degree of crystallinity of natural starch granules had a range from 15 to $45 \%$ [58].
NMR was used for further investigations of crystalline structure for isolated starch. Chemical shifts of ${ }^{13} \mathrm{C} C P / M A S$ NMR for the starch isolated from different sweet and grain varieties studied are shown in Table 4. Molecular order in starch granule is composed of two types of helices from the amylopectin branch chain. The helices that are packed in short-range order are defined as the double helical order, which can be detected by ${ }^{13} \mathrm{C} \mathrm{CP} / \mathrm{MAS} \mathrm{NMR}$ but not by XRD. The helices that are packed in long-range order are related to the packing of double helices forming crystallinity, which can be measured by both ${ }^{13} \mathrm{C} \mathrm{CP/MAS} \mathrm{NMR} \mathrm{and} \mathrm{XRD}$ [61]. Figure 5(a) shows spectral feature of NMR spectra for different sweet and grain sorghum varieties starch. Spectral resonance differences For $\mathrm{C}_{1}$ (which contains information about both crystalline nature as well as noncrystalline nature) were noticed [62]. Currently studied grain varieties and 6 out of 8 of sweet varieties showed a triplet model at $C_{1}$ resonance, as described by Atichokudomchai et al. (2004) [61] and, therefore, showed $\mathrm{C}_{\mathrm{A}}$ type starch as discussed in Bogracheva et al. (2001) for the long-range order of starch [63]. $\mathrm{C}_{6}$ resonance did not clearly exhibit differences between sweet and grain varieties as much as those at $\mathrm{C}_{4}$ resonance (Figure 5(c)) and $\mathrm{C}_{1}$ resonance (Figure 5(b)). As shown in Figure $5(\mathrm{~b}), \mathrm{C}_{1}$ resonance of grain varieties had two shoulders at the left side of the abundant peak and one shoulder at the right side. Sweet varieties GL-4 and GL-6 had two shoulders 


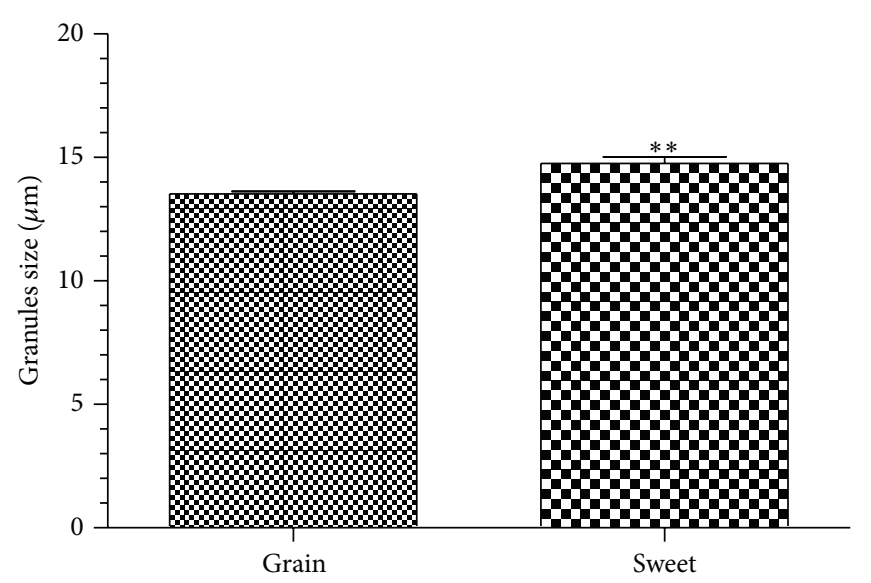

(a)

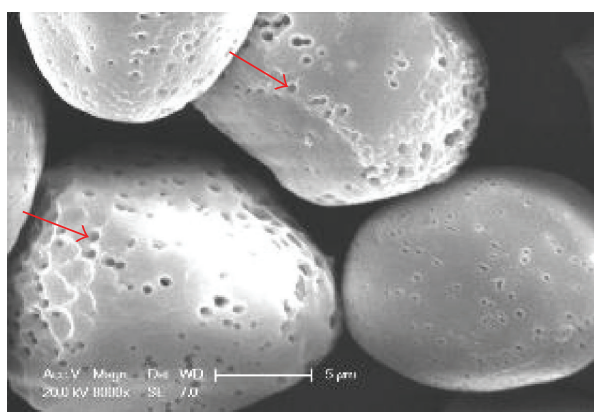

(1)

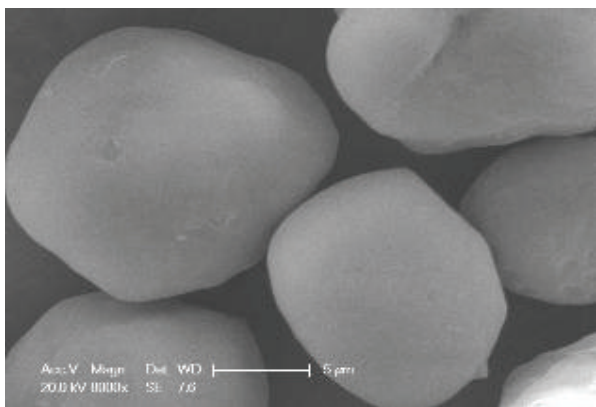

(3)

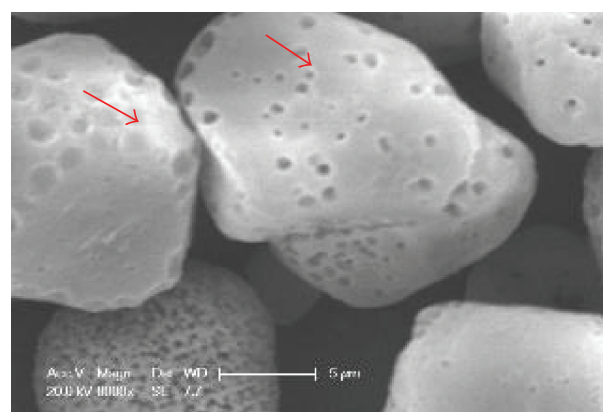

(2)

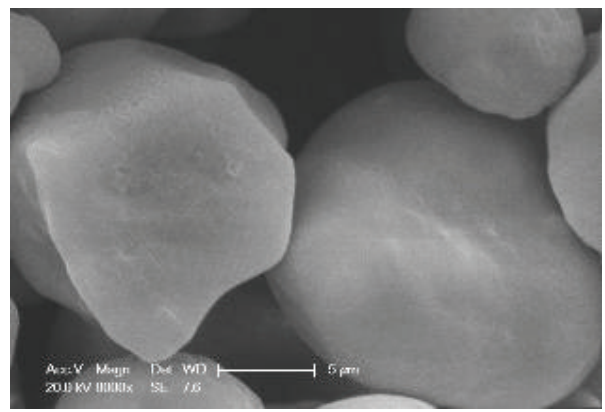

(4)

(b)

FIGURE 7: Comparison of starch granule size (a) and SEM images at magnification of 8000x (b) between sweet and grain varieties. $* *$ means that high significant $(p<0.01)$ difference was noticed. In panel $(b), 1-4$ indicate GL-13, ST, TAT, and WAH, respectively.

at the left side, while at the right side they did not. Sweet varieties ZS and YT look like grain one but the right shoulder showed short extension. Sweet variety GL-13 revealed very short extension for the lower left shoulder, whereas for T-1 and ST the upper left shoulder showed short extension. GL14 had no clear shoulder on the right side, but the left side showed one more extension (Figure $5(\mathrm{~b})$ ). For $\mathrm{C}_{4}$ resonance, all the varieties showed clear differences for appearance of shoulders and peaks (Figure 5(c)). Sweet varieties GL-4 and GL-6 had no peaks appearing. Shoulders at the left side for TAT (81.0 ppm), WAD (80.9 ppm), and GL-1 (80.1 ppm) $1 \mathrm{ppm}$ occur as distinct peaks for ST, GL-14, ARG, and ZS at $80.87,80.72,80.12$, and 79.83 ppm, respectively (Figure 5(c)).
Sweet variety ZS had clear shoulder at the right side at 82.00 ppm and ST had shoulder at 79.58 ppm (Figure 5(c)).

3.5. Morphological Properties of Starch Granule. Scanning electron microscope (SEM) was used to investigate morphology of starch from different sweet and grain sorghum as shown in Figure 6. SEM for starch granules from sweet and grain varieties showed polygonal or spherical shape without clear differences between them in the shape. These results for starch granule shape are in accordance with those reported by Benmoussa et al. (2006) for their study about sorghum starch in America [64] and by Singh et al. (2010) for their study about sorghum starch in India [40] but are little different 


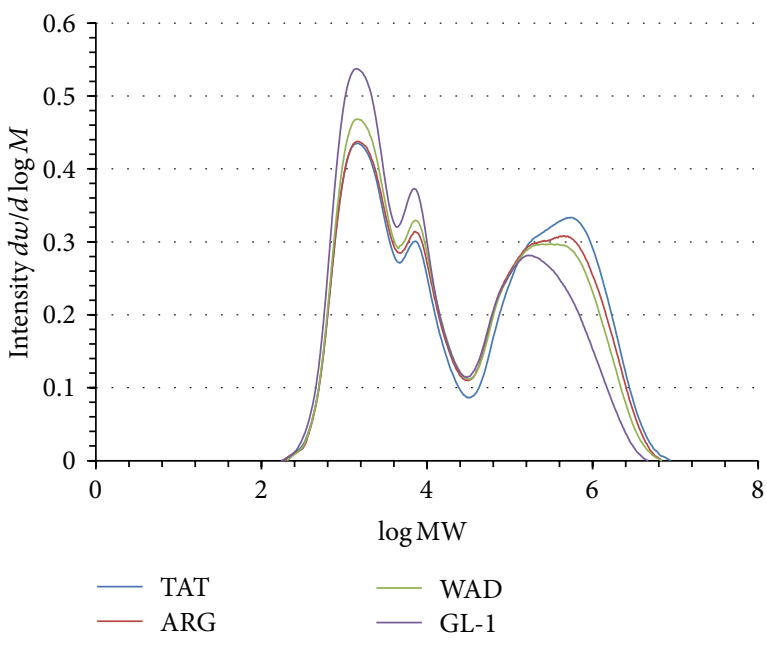

(a)

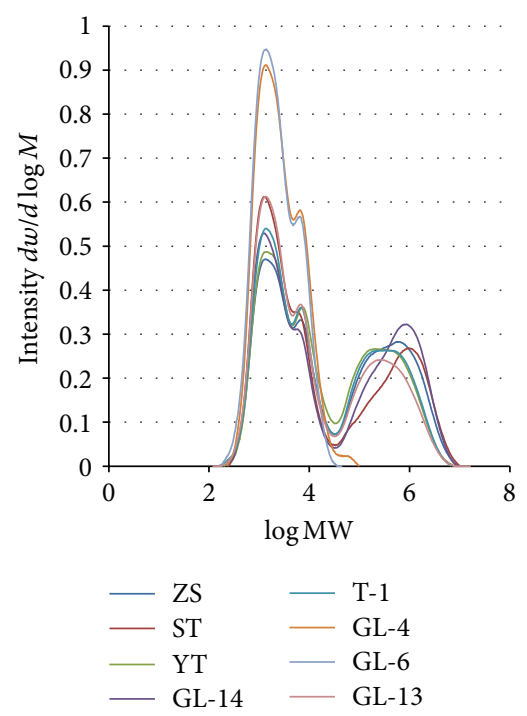

(b)

FIGURE 8: GPC profile for debranched starches from grain (a) and sweet (b) sorghum varieties.

TABLE 5: The starch granules size for different sweet and grain sorghum varieties.

\begin{tabular}{lcccc}
\hline \multirow{2}{*}{ Sample } & \multicolumn{5}{c}{ Granule size $\mu \mathrm{m}$} \\
& Max. & Min. & Mean & SD \pm \\
\hline Grain & & & & \\
GL-1 & 22.51 & 5.23 & 13.63 & 2.63 \\
WAD & 21.35 & 6.040 & 13.38 & 2.86 \\
ARG & 22.45 & 5.718 & 13.35 & 3.07 \\
TAT & 20.58 & 7.345 & 13.74 & 2.69 \\
\hline Sweet & & & & \\
GL-4 & 25.03 & 6.43 & 15.49 & 3.57 \\
GL-6 & 24.44 & 7.45 & 15.67 & 3.58 \\
GL-13 & 22.95 & 6.64 & 14.59 & 2.54 \\
GL-14 & 21.59 & 6.02 & 13.95 & 2.74 \\
ZS & 22.19 & 4.73 & 13.83 & 3.62 \\
YT & 27.44 & 6.61 & 14.46 & 3.61 \\
T-1 & 23.01 & 9.17 & 15.48 & 2.88 \\
ST & 21.69 & 5.47 & 14.66 & 2.80 \\
\hline
\end{tabular}

from those reported by Alvesa et al. (2014) for their study on sweet sorghum juice starch; they noticed predominantly an irregular polyhedral shape and generally an irregular shape [45]. The granules diameters of both sweet and grain varieties starch are presented in Table 5, and their range was from 13.35 to $15.67 \mu \mathrm{m}$. The sweet varieties granule diameter had the range from $13.83 \mu \mathrm{m}$ to $15.67 \mu \mathrm{m}$. Starch from grain varieties had granule size from 13.35 to $13.74 \mu \mathrm{m}$. The granule size of the current study was in the range with that reported in Lindeboom et al. (2004); they summarized the size of starch granules from conventional sources ranges from less than $1 \mu \mathrm{m}$ to more than $100 \mu \mathrm{m}$ [65]. In the same way of comparing current results, Ai et al. (2011) mentioned starch granule size from 4 to $35 \mu \mathrm{m}$ in their study for five genotypes of sorghum [66], whereas Gaffa et al. (2004) reported granule size from 4 to $26 \mu \mathrm{m}$ for their study about white and red sorghum [67]. These differences clarified that this parameter is under genetic control, varying with the variety and environment. Starch from sweet varieties GL- 6 and GL-4 showed the highest granule diameter (15.67 and $15.49 \mu \mathrm{m}$, resp.) in spite of the fact that they had the lowest AC\% (6.71\% and 5.39\%, resp.). From the current study, starch granule size of sweet varieties exhibited significantly $(p<0.05)$ larger size compared to that of grain varieties (Figure 7(a)). Also Gaffa et al. (2004) noticed that the higher amount of large molecules was shown from red sorghum for their study about white and red sorghum starch [67]. The starch from both sweet and grain varieties showed smooth surface in accordance with that reported previously by Sun et al. (2014) [32]. Consequently, sweet varieties showed some dents in surface (Figure 7(b)) which was early mentioned in Sang et al. (2008) [68]. There appeared to be more dents on the surfaces of sweet variety GL-13 (indicated by arrows) (Figure 7(b)). Zhang et al. (2010) [69] and Sun et al. (2014) [32] clarified the existence of holes on the surface of starch granule, but they attributed that to the heat-moisture treatment which led to structural changes. Consequently, in the present study, in which there was no heat-moisture treatment, these dents may indicate that the structure of starch granule is different from those which had no dents, and further investigations are sharply needed. Comparing the current results from sorghum with other starch sources we noticed the following: it was a little different from that of wild Trapa species (Trapa spp.) as reported by Huang et al. (2015) (long axis length was from 15.02 to $16.51 \mu \mathrm{m}$ ) [62], it was even higher than that for rice $(2.0-7.0 \mu \mathrm{m})$ as mentioned by Vandeputte and Delcour (2004) [70], and it was near to that of barely $(2.0-18.1 \mu \mathrm{m})$ as reported by Tang et al. (2004) [31].

3.6. Chains Length Distribution of Starch. The results of chains length distribution for debranched starch from both sweet and grain varieties using gel permeation chromatography (GPC) are presented in Figures $8(\mathrm{a})$ and $8(\mathrm{~b})$. Both 


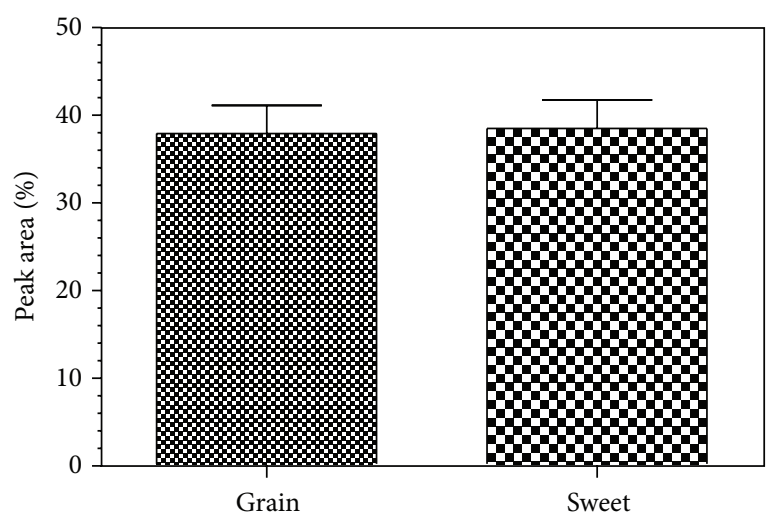

(a)

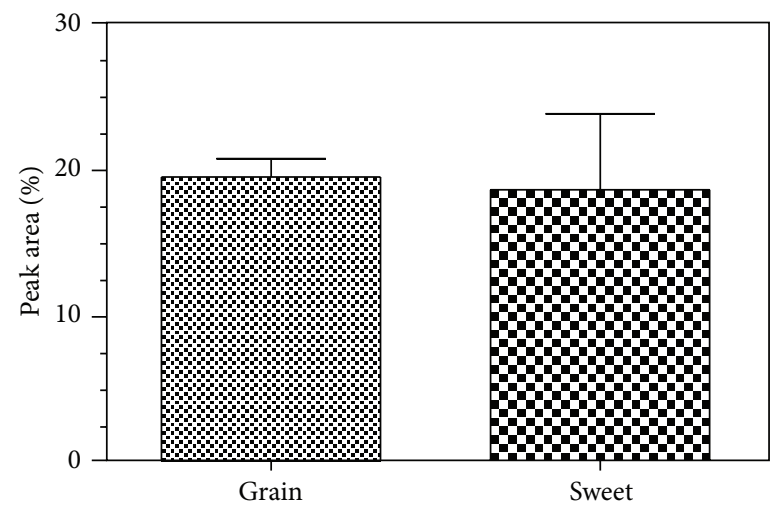

(b)

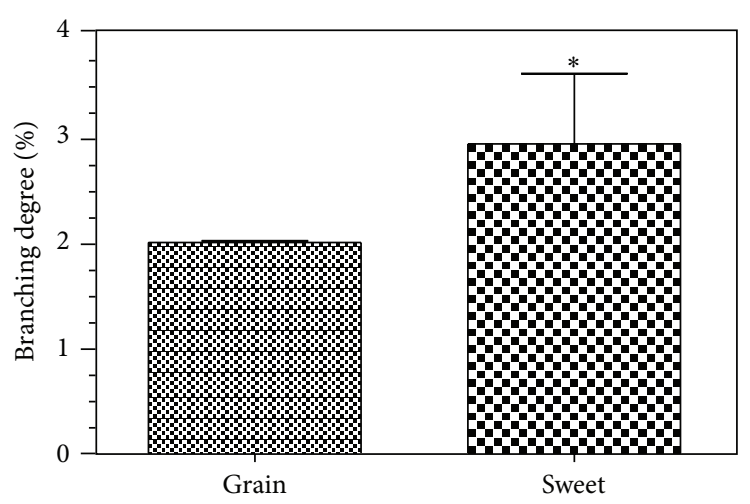

(c)

FIGURE 9: Comparison of peak 1 area (a), peak 2 area (b), and the branching degree (peak 1/peak 2) (c) from GPC profile between sweet and grain varieties starches. $*$ indicates that significant difference was noticed $(p<0.05)$.

TABLE 6: Molecular weight distribution of sweet and grain sorghum starch.

\begin{tabular}{lccc}
\hline Sample & Peak area (\%) \\
& Peak 1 & Peak 1/peak 2 \\
\hline Grain & & & \\
GL-1 & $42.53 \pm 2.50^{\mathrm{b}}$ & $21.17 \pm 0.40^{\mathrm{bc}}$ & $2.01 \pm 0.16^{\mathrm{c}}$ \\
WAD & $39.90 \pm 5.69^{\mathrm{b}}$ & $19.57 \pm 0.38^{\mathrm{bcd}}$ & $2.04 \pm 0.33^{\mathrm{c}}$ \\
ARG & $38.47 \pm 5.48^{\mathrm{b}}$ & $19.17 \pm 1.49^{\mathrm{cd}}$ & $2.00 \pm 0.13^{\mathrm{c}}$ \\
TAT & $36.81 \pm 3.91^{\mathrm{b}}$ & $18.17 \pm 1.74^{\mathrm{cd}}$ & $2.02 \pm 0.02^{\mathrm{c}}$ \\
\hline Sweet & & & \\
GL-4 & $72.78 \pm 0.58^{\mathrm{a}}$ & $27.22 \pm 0.58^{\mathrm{a}}$ & $2.68 \pm 0.08^{\mathrm{abc}}$ \\
GL-6 & $76.02 \pm 0.47^{\mathrm{a}}$ & $23.98 \pm 0.47^{\mathrm{ab}}$ & $3.17 \pm 0.08^{\mathrm{abc}}$ \\
G-13 & $47.03 \pm 0.45^{\mathrm{b}}$ & $17.81 \pm 0.52^{\text {cde }}$ & $2.64 \pm 0.05^{\mathrm{abc}}$ \\
GL-14 & $47.28 \pm 4.92^{\mathrm{b}}$ & $11.96 \pm 0.48^{\mathrm{f}}$ & $3.96 \pm 0.57^{\mathrm{a}}$ \\
ZS & $43.11 \pm 7.02^{\mathrm{b}}$ & $15.44 \pm 3.23^{\mathrm{def}}$ & $2.90 \pm 1.06^{\mathrm{abc}}$ \\
YT & $42.84 \pm 5.20^{\mathrm{b}}$ & $20.63 \pm 0.22^{\mathrm{bc}}$ & $2.08 \pm 0.23^{\mathrm{c}}$ \\
T-1 & $44.24 \pm 4.02^{\mathrm{b}}$ & $18.68 \pm 0.39^{\mathrm{cd}}$ & $2.37 \pm 0.26^{\mathrm{bc}}$ \\
ST & $51.13 \pm 1.19^{\mathrm{b}}$ & $13.26 \pm 0.63^{\mathrm{ef}}$ & $3.86 \pm 0.09^{\mathrm{ab}}$ \\
\hline All &
\end{tabular}

All data represent the mean of two determinations.

Means with the same superscript in each column are not significantly different $(p<0.05)$.

sweet and grain varieties showed typical GPC chromatogram of debranched starch. A tri-modal of peaks for chains length distribution was observed and designated as peak 1 , peak 2 , and peak 3, respectively. Peak 1 and peak 2 refer to amylopectin (AP) fraction representing the short branch chains (A and short B chains) and long branch chains (long B chains), respectively, while peak 3 refers to amylose fraction (AM) as mentioned in Song and Jane (2000) [71]. The area percentage of peaks from the GPC chromatographs was used to compare the weight distribution of chains for AP and AM fractions. All varieties showed significant differences $(p<$ 0.05 ) as shown in Table 6 . Peak 1 showed that short chains are the major group and exhibited the range from 36.81 to $76.02 \%$ for TAT and GL-6, respectively, while peak 2 showed the range from 11.96 to $27.22 \%$ for GL-14 and GL-4, respectively. The branching degree of AP (peak 1/peak 2) was from 2.00 to $3.96 \%$ for ARG and GL-14, respectively. Sweet varieties studied were not significantly $(p<0.05)$ different from grain varieties for peak 1 (Figure 9(a)) and peak 2 (Figure 9(b)), whereas for branching degree significant difference $(p<$ 0.05 ) was noticed (Figure 9(c)). For the appearance of peaks and shoulders for the AM fraction, sweet varieties were categorized in four groups: (GL-13, YT, and T-1), ZS, (ST and GL-14), and (GL-6 and GL-4) (Figure 8(b)), whereas grain varieties were categorized in three groups: WAD, GL-1, and TAT and ARG (Figure 8(a)). As shown in Figure 8(a) grain varieties WAD, ARG, and TAT have two AM components, while GL-1 only has one. For sweet varieties Figure 8(b) shows 
that all varieties almost have two components for AM fraction except GL-4 and GL-6. The existence of two components of AM fraction is in accordance with what was reported by Wang et al. (2014) [72]. Sweet variety ZS looks like grain varieties (ARG, WAD, and TAT) showing left shoulder and a little peak for AM fraction.

\section{Conclusion}

From the above-mentioned data, it can be concluded that sweet varieties exhibited little differences from grain varieties and some of them look like grain ones, which indicates the possibility to use their starches for industrialization as their grains are not preferable in food. All grain varieties showed high AC content, while some sweet varieties reflected very low AC content and others showed intermediate content. The current results showed that the essence of sweet and grain in sorghum plant beside accumulation of high sugar in stems was also affected by amylose and amylopectin fractions which affect the physical and chemical properties of their grain starch. Wide range shown in current study for AC content keeps sorghum out of altering the proportions of amylose and amylopectin, which makes it preferable for commercial uses.

\section{Competing Interests}

The authors declare that they have no competing interests.

\section{Acknowledgments}

This study was funded by the Ministry of Agriculture of China (Grant 2016 ZX 08009003-004), the Ministry of Science and Technology of China (Grant 2012 CB 944803), and Jiangsu PAPD and Qing Lan Projects.

\section{References}

[1] J. R. N. Taylor, T. J. Schober, and S. R. Bean, "Novel food and non-food uses for sorghum and millets," Journal of Cereal Science, vol. 44, no. 3, pp. 252-271, 2006.

[2] A. E. O. Elkhalifa and R. Bernhardt, "Some physicochemical properties of flour from germinated sorghum grain," Journal of Food Science and Technology, vol. 50, no. 1, pp. 186-190, 2013.

[3] S. Bhoyar and R. Thakare, "Ethanol recovery and biological studies of some elite sweet sorghum cultivars," Indian Journal of Agricultural Research, vol. 43, no. 2, pp. 139-143, 2009.

[4] C. Junfeng, "A study on the accumulation and distribution of dry matter in post-flowered sweet sorghum," Acta Botanica Boreali-Occidentalia Sinica, vol. 17, no. 2, pp. 221-225, 1997.

[5] C. Zhang, G. Xie, S. Li, L. Ge, and T. He, "The productive potentials of sweet sorghum ethanol in China," Applied Energy, vol. 87, no. 7, pp. 2360-2368, 2010.

[6] A. E. O. Elkhalifa, B. Schiffler, and R. Bernhardt, "Selected physicochemical properties of starch isolated from fermented sorghum flour," Starch, vol. 56, no. 12, pp. 582-585, 2004.

[7] N. Boudries, N. Belhaneche, B. Nadjemi et al., "Physicochemical and functional properties of starches from sorghum cultivated in the Sahara of Algeria," Carbohydrate Polymers, vol. 78, no. 3, pp. $475-480,2009$.
[8] I. S. Udachan, A. K. Sahoo, and G. M. Hend, "Extraction and characterization of sorghum (sorghum bicolor L. moench) starch," International Food Research Journal, vol. 19, no. 1, pp. 315-319, 2012.

[9] H. Singh, Y. H. Chang, J.-H. Lin, N. Singh, and N. Singh, "Influence of heat-moisture treatment and annealing on functional properties of sorghum starch," Food Research International, vol. 44, no. 9, pp. 2949-2954, 2011.

[10] J. W. Donovan, "Phase transitions of the starch-water system," Biopolymers, vol. 18, no. 2, pp. 263-275, 1979.

[11] D. B. Lund, "Influence of time, temperature, moisture, ingredients, and processing conditions on starch gelatinization," $C R C$ Critical Reviews in Food Science and Nutrition, vol. 20, no. 4, pp. 249-273, 1984

[12] R. L. Shogren, "Effect of moisture content on the melting and subsequent physical aging of cornstarch," Carbohydrate Polymers, vol. 19, no. 2, pp. 83-90, 1992.

[13] K. Tananuwong and D. S. Reid, "DSC and NMR relaxation studies of starch-water interactions during gelatinization," Carbohydrate Polymers, vol. 58, no. 3, pp. 345-358, 2004.

[14] A.-M. Hermansson and K. Svegmark, "Developments in the understanding of starch functionality," Trends in Food Science \& Technology, vol. 7, no. 11, pp. 345-353, 1996.

[15] R. F. Tester and W. R. Morrison, "Swelling and gelatinization of cereal starches, I. Effect of amylopectin, amylose and lipids," Cereal Chemistry, vol. 67, pp. 551-557, 1990.

[16] R. F. Tester and W. R. Morrison, "Swelling and gelatinization of cereal starches. VI. Starches from waxy hector and hector barleys at four stages of grain development," Journal of Cereal Science, vol. 17, no. 1, pp. 11-18, 1993.

[17] H. F. Zobel, "Gelatinization of starch and mechanical properties of starch pastes," in Starch: Chemistry and Technology, R. Whistler, J. N. Bemiller, and E. F. Paschall, Eds., pp. 285-309, Academic Press, Orlando, Fla, USA, 1984.

[18] H. Liu, L. Yu, F. Xie, and L. Chen, "Gelatinization of cornstarch with different amylose/amylopectin content," Carbohydrate Polymers, vol. 65, no. 3, pp. 357-363, 2006.

[19] N. W. H. Cheetham and L. Tao, "Variation in crystalline type with amylose content in maize starch granules: an X-ray powder diffraction study," Carbohydrate Polymers, vol. 36, no. 4, pp. 277-284, 1998

[20] H. Saitô, T. Yukumoto, H. Yajima, R. Endo, and J. Yamada, "Conformational stability of V-amyloses and their hydrationinduced conversion to B-type form as studied by highresolution solid-state ${ }^{13} \mathrm{C}$ NMR spectroscopy," Bulletin of the Chemical Society of Japan, vol. 64, no. 12, pp. 3528-3537, 1991.

[21] H. J. Gidley and S. M. Bocick, "Maize starches from four wx-containing genotypes of the W64A inbred line in relation to gelatinization and retrogradation," Journal of the American Chemical Society, vol. 107, pp. 7040-7044, 1985.

[22] D. Cooke and M. J. Gidley, "Loss of crystalline and molecular order during starch gelatinisation: origin of the enthalpic transition," Carbohydrate Research, vol. 227, pp. 103-112, 1992.

[23] A. Xu and P. A. Seib, "Determination of the level and position of substitution in hydroxypropylated starch by high-resolution $1 \mathrm{H}-\mathrm{NMR}$ spectroscopy of alpha-limit dextrins," Journal of Cereal Science, vol. 25, no. 1, pp. 17-26, 1997.

[24] Z. A. Syahariza, E. Li, and J. Hasjim, "Extraction and dissolution of starch from rice and sorghum grains for accurate structural analysis," Carbohydrate Polymers, vol. 82, no. 1, pp. 14-20, 2010. 
[25] S.-H. Yoo and J.-L. Jane, "Molecular weights and gyration radii of amylopectins determined by high-performance sizeexclusion chromatography equipped with multi-angle laserlight scattering and refractive index detectors," Carbohydrate Polymers, vol. 49, no. 3, pp. 307-314, 2002.

[26] S. R. Erlander and S. Tobin, "The stability of the helix of amylose and amylopectin in DMSO and water solutions," Die Makromolekulare Chemie, vol. 111, no. 1, pp. 194-211, 1968.

[27] N. Lumdubwong and P. A. Seib, "Rice starch isolation by alkaline protease digestion of wet-milled rice flour," Journal of Cereal Science, vol. 31, no. 1, pp. 63-74, 2000.

[28] Standard for Ministry of Agriculture of the People's Republic of China, NY 147-88: Quality Measurement Method for Rice, China Standard Press, Beijing, China, 1st edition, 1989.

[29] G. B. Cagampang, C. M. Perez, and B. O. Juliano, "A gel consistency test for eating quality of rice," Journal of the Science of Food and Agriculture, vol. 24, no. 12, pp. 1589-1594, 1973.

[30] S. Radosta, B. Kettlitz, F. Schierbaum, Bergholz-Rehbriicke, and C. Gemat, "Studies on rye starch properties and modification. Part II: swelling and solubility behavior of rye starch granules," SfarcW Stiirke, vol. 43, pp. 33 1-339, 1991.

[31] H. Tang, T. Mitsunaga, and Y. Kawamura, "Relationship between functionality and structure in barley starches," Carbohydrate Polymers, vol. 57, no. 2, pp. 145-152, 2004.

[32] Q. Sun, Z. Han, L. Wang, and L. Xiong, "Physicochemical differences between sorghum starch and sorghum flour modified by heat-moisture treatment," Food Chemistry, vol. 145, pp. 756764, 2014

[33] S. Nara and T. Komiya, "Studies on the relationship between water-satured state and crystallinity by the diffraction method for moistened potato starch," Starch, vol. 35, no. 12, pp. 407-410, 1983.

[34] D. A. Torchia, "The measurement of proton-enhanced carbon13 T1 values by a method which suppresses artifacts," Journal of Magnetic Resonance, vol. 30, no. 3, pp. 613-616, 1978.

[35] J. Spěváček, J. Brus, T. Divers, and Y. Grohens, "Solid-state NMR study of biodegradable starch/polycaprolactone blends," European Polymer Journal, vol. 43, no. 5, pp. 1866-1875, 2007.

[36] A. O. Ashogbon and E. T. Akintayo, "Morphological, functional and pasting properties of starches separated from rice cultivars grown in Nigeria," International Food Research Journal, vol. 19, no. 2, pp. 665-671, 2012.

[37] M. Asaoka, K. Okuno, and H. Fuwa, "Effect of environmental temperature at the milky stage on amylose content and fine structure of amylopectin of waxy and nonwaxy endosperm starches of rice (Oryza sativa L.)," Agricultural and Biological Chemistry, vol. 49, no. 2, pp. 373-379, 1985.

[38] L.-J. Zhu, Q.-Q. Liu, Y. Sang, M.-H. Gu, and Y.-C. Shi, "Underlying reasons for waxy rice flours having different pasting properties," Food Chemistry, vol. 120, no. 1, pp. 94-100, 2010.

[39] H. Chanapamokkhot and M. Thongngam, "The chemical and physico-chemical properties of sorghum starch and flour," Kasetsart Journal (Natural Science), vol. 41, pp. 343-349, 2007.

[40] H. Singh, N. S. Sodhi, and N. Singh, "Characterisation of starches separated from sorghum cultivars grown in India," Food Chemistry, vol. 119, no. 1, pp. 95-100, 2010.

[41] T. Beta, H. Corke, J. R. N. Taylor, and L. W. Rooney, "Effect of steeping treatment on pasting and thermal properties of sorghum starches," Cereal Chemistry, vol. 78, no. 3, pp. 303-306, 2001.
[42] F. Zhu, "Structure, physicochemical properties, modifications, and uses of sorghum starch," Comprehensive Reviews in Food Science and Food Safety, vol. 13, no. 4, pp. 597-610, 2014.

[43] H. Hill, L. Slade Lee, and R. J. Henry, "Variation in sorghum starch synthesis genes associated with differences in starch phenotype," Food Chemistry, vol. 131, no. 1, pp. 175-183, 2012.

[44] M. Schirmer, A. Höchstötter, M. Jekle, E. Arendt, and T. Becker, "Physicochemical and morphological characterization of different starches with variable amylose/amylopectin ratio," Food Hydrocolloids, vol. 32, no. 1, pp. 52-63, 2013.

[45] F. V. Alvesa, L. F. Polesib, C. L. Aguiara, and S. B. S. Sarmentoa, "Structural and physicochemical characteristics of starch from sugarcane and sweet sorghum stalks," Carbohydrate Polymers, vol. 111, pp. 592-597, 2014.

[46] Y. Lu, G. Zhao, Y. Li et al., "Identification of two novel waxy alleles and development of their molecular markers in sorghum," Genome, vol. 56, no. 5, pp. 283-288, 2013.

[47] I. Lindqvist, "Cold gelatinization of starch," Starch, vol. 31, no. 6, pp. 195-200, 1979.

[48] R. Hoover, "Composition, molecular structure, and physicochemical properties of tuber and root starches: a review," Carbohydrate Polymers, vol. 45, no. 3, pp. 253-267, 2001.

[49] L. Kaur, N. Singh, and N. S. Sodhi, "Some properties of potatoes and their starches. II. Morphological, thermal and rheological properties of starches," Food Chemistry, vol. 79, no. 2, pp. 183192, 2002.

[50] M. Carcea and R. Acquistucci, "Isolation and physicochemical characterization of fonio (Digitaria exilis stapf) starch," Starch/Staerke, vol. 49, no. 4, pp. 131-135, 1997.

[51] N. Singh, J. Singh, L. Kaur, N. S. Sodhi, and B. S. Gill, "Morphological, thermal and rheological properties of starches from different botanical sources," Food Chemistry, vol. 81, no. 2, pp. 219-231, 2003.

[52] S. N. Subrahmanyam and R. C. Hoseney, "Shear thinning properties of sorghum starch," Cereal Chemistry, vol. 72, pp. 710, 1995.

[53] O. O. Olayinka, K. O. Adebowale, and B. I. Olu-Owolabi, "Effect of heat-moisture treatment on physicochemical properties of white sorghum starch," Food Hydrocolloids, vol. 22, no. 2, pp. 225-230, 2008.

[54] C. Wei, F. Qin, W. Zhou et al., "Comparison of the crystalline properties and structural changes of starches from highamylose transgenic rice and its wild type during heating," Food Chemistry, vol. 128, no. 3, pp. 645-652, 2011.

[55] J. Hasjim, E. Li, and S. Dhital, "Milling of rice grains: effects of starch/flour structures on gelatinization and pasting properties," Carbohydrate Polymers, vol. 92, no. 1, pp. 682-690, 2013.

[56] Y. Ji, Z. Ao, J.-A. Han, J.-L. Jane, and J. N. BeMiller, "Waxy maize starch subpopulations with different gelatinization temperatures," Carbohydrate Polymers, vol. 57, no. 2, pp. 177-190, 2004.

[57] J. O. Akingbala, M. H. Gomez, L. W. Rooney, and V. E. Sweat, "Thermal properties of sorghum starch," Starch, vol. 40, no. 10, pp. 375-378, 1988.

[58] H. F. Zobel, "Starch crystal transformations and their industrial importance," Starch, vol. 40, no. 1, pp. 1-7, 1988.

[59] S. I. Shin, H. J. Choi, K. M. Chung, B. R. Hamaker, K. H. Park, and T. W. Moon, "Slowly digestible starch from debranched waxy sorghum starch: preparation and properties," Cereal Chemistry, vol. 81, no. 3, pp. 404-408, 2004. 
[60] M. G. Sajilata, R. S. Singhal, and P. R. Kulkarni, "Resistant starch-a review," Comprehensive Reviews in Food Science and Food Safety, vol. 5, no. 1, pp. 1-17, 2006.

[61] N. Atichokudomchai, S. Varavinit, and P. Chinachoti, "A study of ordered structure in acid-modified tapioca starch by ${ }^{13} \mathrm{C}$ CP/MAS solid-state NMR," Carbohydrate Polymers, vol. 58, no. 4, pp. 383-389, 2004.

[62] J. Huang, L. Zhao, H. Huai, E. Li, F. Zhang, and C. Wei, "Structural and functional properties of starches from wild Trapa quadrispinosa, japonica, mammillifera and incisa," Food Hydrocolloids, vol. 48, pp. 117-126, 2015.

[63] T. Y. Bogracheva, Y. L. Wang, and C. L. Hedley, "The effect of water content on the ordered/disordered structures in starches," Biopolymers, vol. 58, no. 3, pp. 247-259, 2001.

[64] M. Benmoussa, B. Suhendra, A. Aboubacar, and B. R. Hamaker, "Distinctive sorghum starch granule morphologies appear to improve raw starch digestibility," Starch, vol. 58, no. 2, pp. 92-99, 2006.

[65] N. Lindeboom, P. R. Chang, and R. T. Tyler, "Analytical, biochemical and physicochemical aspects of starch granule size, with emphasis on small granule starches: a review," Starch, vol. 56, no. 3-4, pp. 89-99, 2004.

[66] Y. Ai, J. Medic, H. Jiang, D. Wang, and J.-L. Jane, "Starch characterization and ethanol production of sorghum," Journal of Agricultural and Food Chemistry, vol. 59, no. 13, pp. 73857392, 2011.

[67] T. Gaffa, Y. Yoshimoto, I. Hanashiro, O. Honda, S. Kawasaki, and Y. Takeda, "Physicochemical properties and molecular structures of starches from millet (Pennisetum typhoides) and sorghum (Sorghum bicolor L. Moench) cultivars in Nigeria," Cereal Chemistry, vol. 81, no. 2, pp. 255-260, 2004.

[68] Y. Sang, S. Bean, P. A. Seib, J. Pedersen, and Y.-C. Shi, "Structure and functional properties of sorghum starches differing in amylose content," Journal of Agricultural and Food Chemistry, vol. 56, no. 15, pp. 6680-6685, 2008.

[69] J. Zhang, F. Chen, F. Liu, and Z.-W. Wang, "Study on structural changes of microwave heat-moisture treated resistant Canna edulis Ker starch during digestion in vitro," Food Hydrocolloids, vol. 24, no. 1, pp. 27-34, 2010.

[70] G. E. Vandeputte and J. A. Delcour, "From sucrose to starch granule to starch physical behaviour: a focus on rice starch," Carbohydrate Polymers, vol. 58, no. 3, pp. 245-266, 2004.

[71] Y. Song and J. Jane, "Characterization of barley starches of waxy, normal, and high amylose varieties," Carbohydrate Polymers, vol. 41, no. 4, pp. 365-377, 2000.

[72] K. Wang, J. Hasjim, A. C. Wu, R. J. Henry, and R. G. Gilbert, "Variation in amylose fine structure of starches from different botanical sources," Journal of Agricultural and Food Chemistry, vol. 62, no. 19, pp. 4443-4453, 2014. 

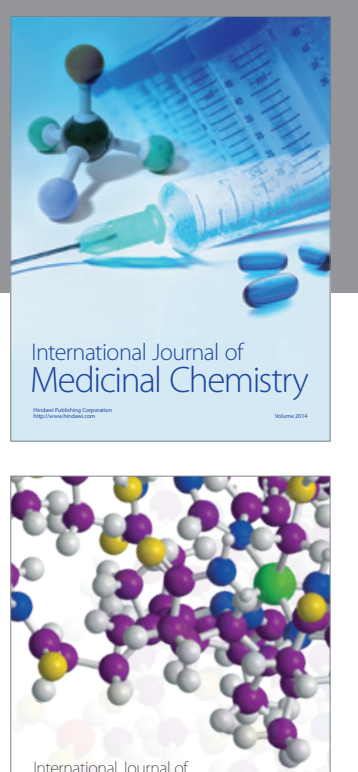

Carbohydrate Chemistry

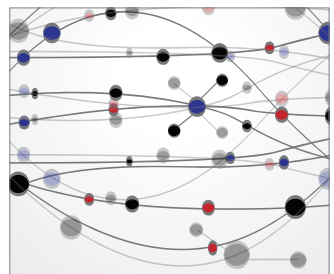

The Scientific World Journal
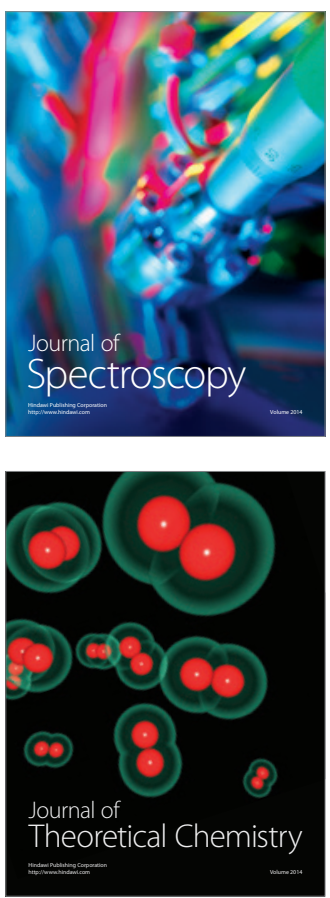
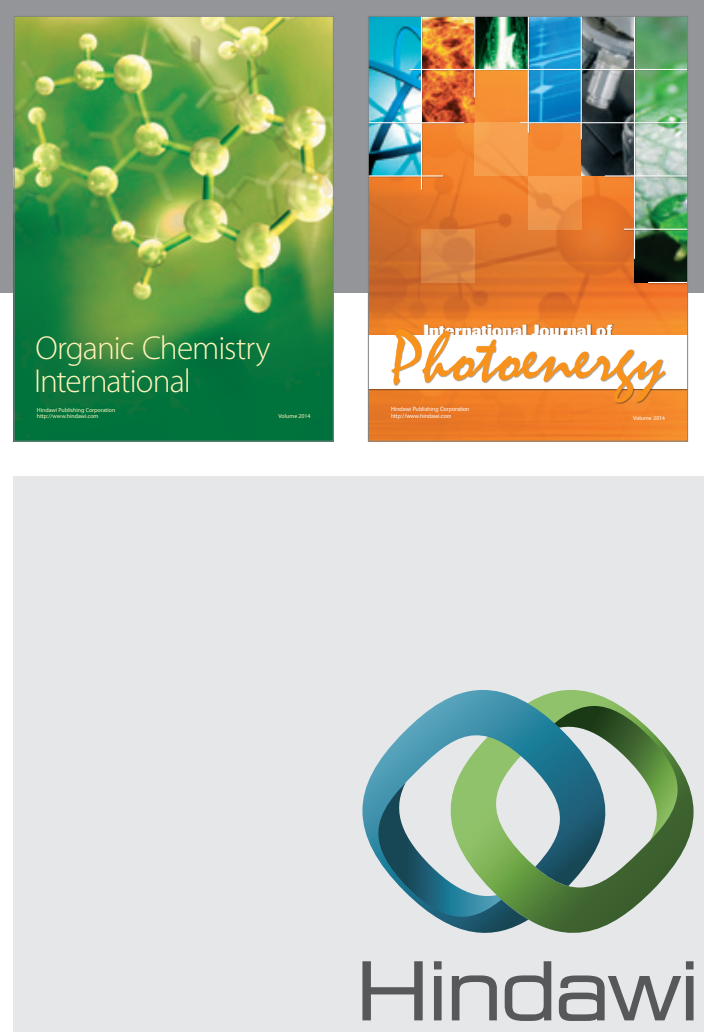

Submit your manuscripts at

http://www.hindawi.com

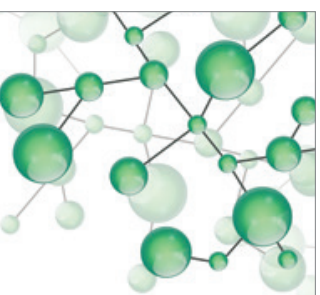

International Journal of

Inorganic Chemistry

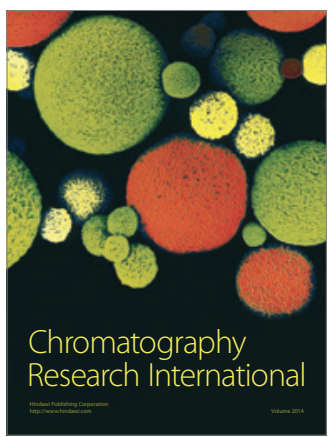

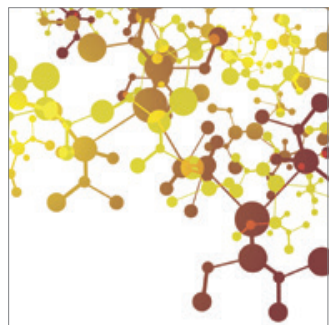

Applied Chemistry
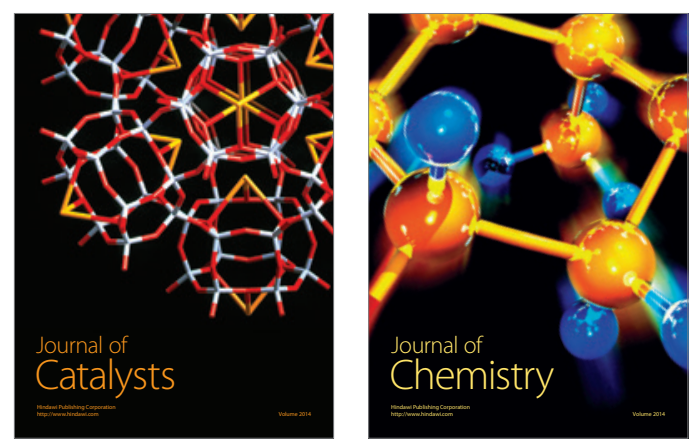
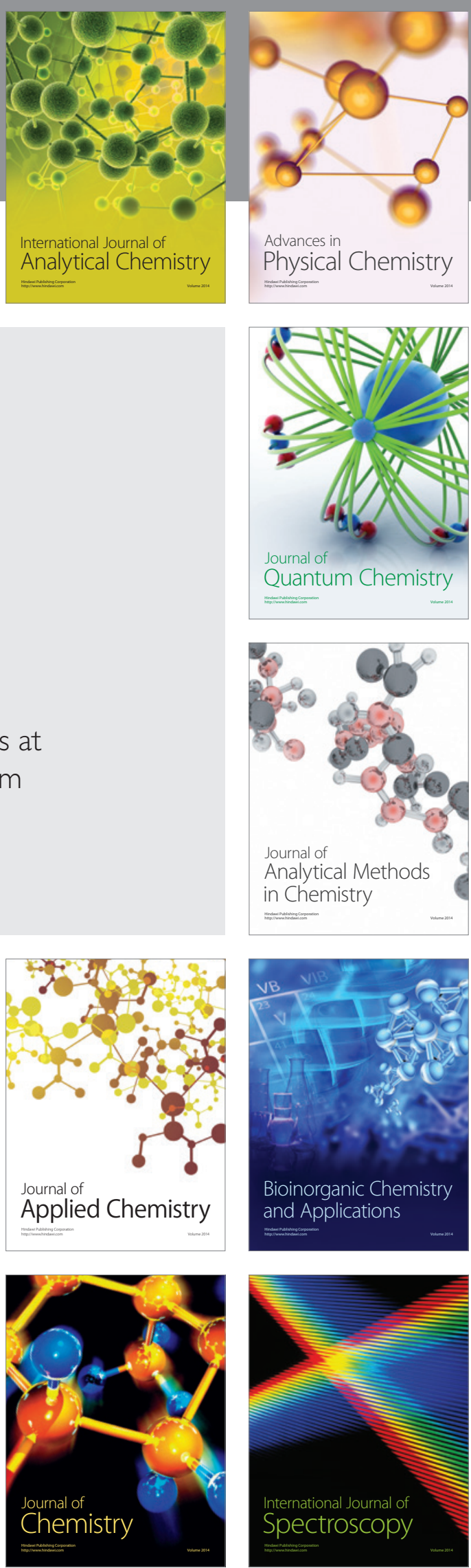